\title{
A Physically Based Multisensor Quantitative Precipitation Estimation Approach for Gap-Filling Radar Coverage
}

\author{
Steven M. Martinaitis, Andrew P. Osborne, And Micheal J. Simpson \\ Cooperative Institute for Mesoscale Meteorological Studies, University of Oklahoma, and NOAA/OAR/National Severe \\ Storms Laboratory, Norman, Oklahoma \\ JIAN ZHANG AND KENNETH W. HOWARD \\ NOAA/OAR/National Severe Storms Laboratory, Norman, Oklahoma \\ Stephen B. Cocks, Ami Arthur, CARrie Langston, And Brian T. KANey \\ Cooperative Institute for Mesoscale Meteorological Studies, University of Oklahoma, and NOAA/OAR/National Severe \\ Storms Laboratory, Norman, Oklahoma
}

(Manuscript received 8 November 2019, in final form 31 March 2020)

\begin{abstract}
Weather radars and gauge observations are the primary observations to determine the coverage and magnitude of precipitation; however, radar and gauge networks have significant coverage gaps, which can underrepresent or even miss the occurrence of precipitation. This is especially noticeable in mountainous regions and in shallow precipitation regimes. The following study presents a methodology to improve spatial representations of precipitation by seamlessly blending multiple precipitation sources within the Multi-Radar Multi-Sensor (MRMS) system. A high spatiotemporal resolution multisensor merged quantitative precipitation estimation (QPE) product (MSQPE) is generated by using gauge-corrected radar QPE as a primary precipitation source with a combination of hourly gauge observations, monthly precipitation climatologies, numerical weather prediction short-term precipitation forecasts, and satellite observations to use in areas of insufficient radar coverage. The merging of the precipitation sources is dependent upon radar coverage based on an updated MRMS radar quality index, surface and atmospheric conditions, topography, gauge locations, and precipitation values. Evaluations of the MSQPE product over the western United States resulted in improved statistical measures over its individual input precipitation sources, particularly the locally gauge-corrected radar QPE. The MSQPE scheme demonstrated its ability to sufficiently fill in areas where radar alone failed to detect precipitation due to significant beam blockage or poor coverage while minimizing the generation of false precipitation and underestimation biases that resulted from radar overshooting precipitation.
\end{abstract}

\section{Introduction}

Accurate, high spatiotemporal resolution quantitative precipitation estimates (QPEs) are crucial for flood and flash flood operations, hydrologic forecasting, long-term climatological evaluations, and water resource management. One common source of measuring precipitation are rain gauges, which provide direct surface measurements; however, a single gauge observation based on an orifice of $80-325 \mathrm{~cm}^{2}$ typically covers a region spanning many square kilometers. Large distances

\footnotetext{
Corresponding author: Steven M. Martinaitis, steven.martinaitis@ noaa.gov
}

between gauge sites can provide an insufficient representation of precipitation. Quina (2003) showed in Florida that the correlation of gauge observations decreased significantly when the distance of nearest neighbor comparisons increased to $20 \mathrm{~km}$ with continued correlated degradation up to a range of $100 \mathrm{~km}$. Comparisons between gauge observations at a distance of $20 \mathrm{~km}$ yielded a correlation of approximately 0.30 for hourly accumulations and 0.55 for daily accumulations. Young et al. (2000) found a similar decrease in correlation between nearest neighbor gauge observations with increasing distance utilizing gauge networks in Oklahoma.

Weather radars provide the spatial resolution and distribution of precipitation that gauge-based point 


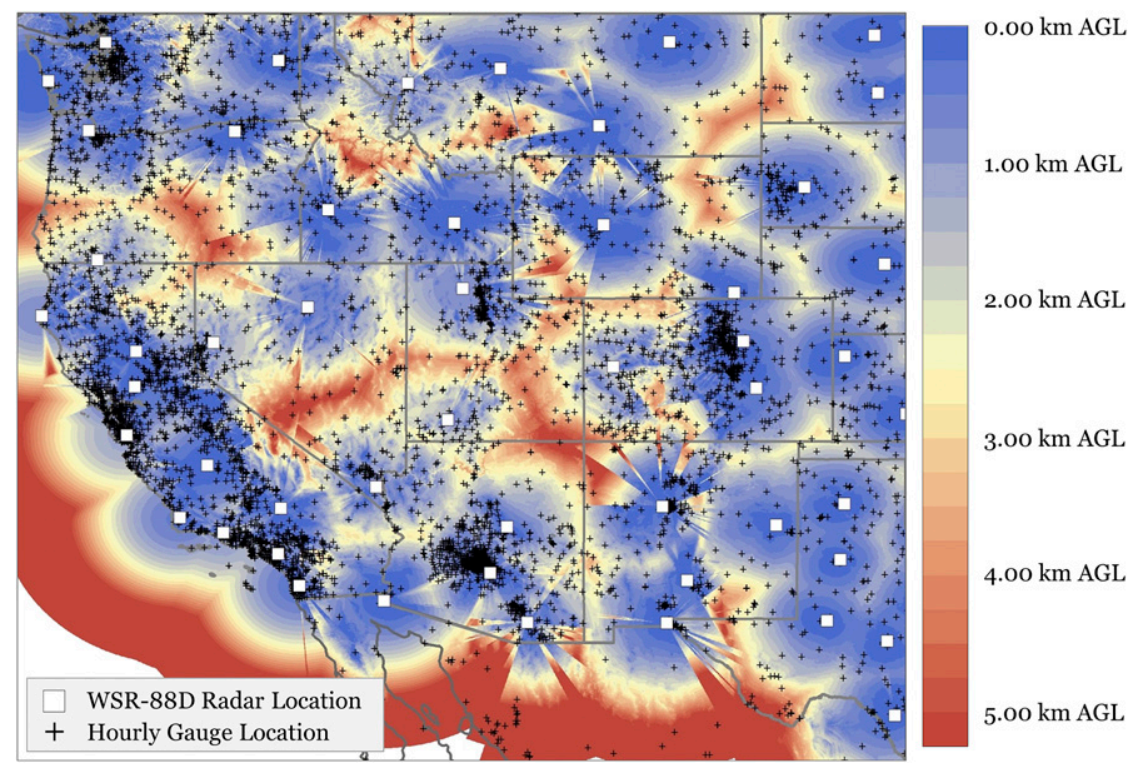

FIG. 1. Height of the bottom of the lowest available radar beam (color fill) per the MRMS seamless hybrid scan reflectivity height product (Zhang et al. 2016) over the CONUS west of $100.0^{\circ} \mathrm{W}$ longitude along with the locations of hourly gauge observations per the MRMS system.

observations cannot, yet the estimated precipitation has greater uncertainty due to it being remotely sensed at varying elevations above the surface. Radar sampling is impacted by large spatial distances between radar sites along with range degradation and blockages in complex terrain, resulting in undersampled precipitation (e.g., Kitchen et al. 1994; Smith et al. 1996; Steiner et al. 1999; Germann and Joss 2002; Zhang et al. 2012a). Maddox et al. (2002) provides a detailed description of the restricted coverage of the Weather Surveillance Radar-1988 Doppler (WSR-88D) network at various height levels. Coverage gaps within gauge and radar networks exist in varying degrees across the contiguous United States (CONUS) and are more prominent in the western CONUS (Fig. 1).

Gauge observations and radar-derived QPEs have been combined in various methodologies to improve precipitation estimations, especially in the context of advancing radar-derived QPE accuracy (e.g., Seo and Breidenbach 2002; Smith and Krajewski 1991); however, bias adjustments of radar-derived precipitation estimates using gauge observations are only applicable where radar coverage is available. Zhang et al. (2014) defined a conceptual methodology of supplementing radar-derived QPE with a Mountain Mapper QPE product (Schaake et al. 2004) generated from hourly gauge observations interpolated onto Parameter-Elevation Regressions on Independent Slopes Model (PRISM; Daly et al. 2008, 1994) monthly precipitation climatologies.
The scheme did not fully compensate for radar coverage gaps but utilized a linear longitudinal blend that used radarbased QPE only east of $100^{\circ} \mathrm{W}$ longitude and Mountain Mapper QPE only west of $118^{\circ} \mathrm{W}$ longitude. This consequently limited or removed any radar data within the intermountain western CONUS and along the Pacific coast, including regions with unobstructed radar coverage.

Other precipitation sources can also be utilized to compensate for gaps in radar and gauge observational coverage. The quality of numerical weather prediction (NWP) quantitative precipitation forecasts (QPFs), notably those generated by short-range convective allowing models (CAMs), has substantially improved skill (e.g., Clark et al. 2009; Sun et al. 2014; Yussouf et al. 2016). An assessment of two versions of the High Resolution Rapid Refresh (HRRR; Benjamin et al. 2016) modeling system along with the prototype National Severe Storms Laboratory (NSSL) Warn-on-Forecast (WoF) system by Lawson et al. (2018) demonstrated the significant progress made with $0-3-\mathrm{h}$ QPFs via advanced data assimilation methods; moreover, Lundquist et al. (2019) describes how high-resolution NWP models can better represent total annual precipitation than the current collection of gauge observations in mountainous terrain. Numerous studies assessed the quality of polar-orbiting and geostationary satellite-derived QPEs and discussed the potential for satellite-derived fields to mitigate radar coverage limitations (e.g., Kuligowski 2010; Scofield and Kuligowski 2003; Stenz et al. 2016). 
The following study describes a physically based approach to improve the spatial representation of precipitation by seamlessly blending various precipitation sources with the current radar coverage over the CONUS. Each precipitation input is weighted based on their observational strengths and accuracy that vary based on atmospheric and terrain properties. The objective is to generate a high spatiotemporal resolution multisensor merged QPE product (hereinafter denoted as MSQPE) within the Multi-Radar Multi-Sensor (MRMS) real-time system (Zhang et al. 2016).

\section{Gap-filling scheme inputs}

\section{a. Precipitation inputs and strengths}

In situ and remotely sensed precipitation along with precipitation climatologies and NWP QPFs are utilized within the MSQPE scheme. Precipitation inputs from the MRMS system include the locally gauge-corrected (LGC) radar QPE and Mountain Mapper QPE. Both products are generated every hour on a 1-km Cartesian grid. Weather radar data for MRMS are gathered from NWS dual-polarization WSR-88D radar network in the CONUS and $30 \mathrm{C}$-band single-polarization weather radars across southern Canada operated by Environment Canada. Quality control of radar data is performed for each radar site to reduce the impacts of nonmeteorological echoes (Tang et al. 2014; Zhang et al. 2016). Other corrections are applied to improve data quality, including the mitigation of beam blockages, data corruption from nonmeteorological features (e.g., wind farms), and brightband contamination (Zhang and Qi 2010; Zhang et al. 2012b; Qi et al. 2013a,b; Zhang et al. 2016). Precipitation rates were generated using an experimental dual-polarization synthetic QPE scheme in the MRMS framework for radar sites utilizing dual-polarization technology (Zhang et al. 2020). Instantaneous rates were calculated from various dual-polarization variables, including specific attenuation, which has immunity to radar calibration errors and some partial beam blockage (Wang et al. 2019). Radars without dual-polarization capabilities utilized reflectivity values to derive precipitation rates (Zhang et al. 2016). Derived precipitation rates are then modified to account for the evaporation of hydrometeors between the lowest utilized radar beam height and the surface (Martinaitis et al. 2018).

MRMS LGC radar QPE and Mountain Mapper QPE rely upon automated hourly gauge observations that pass quality control measures. MRMS ingests approximately 20000 gauge observations per hour across the MRMS CONUS domain from the Hydrometeorological Automated Data System (HADS; Kim et al. 2009) and the Meteorological Assimilation Data Ingest System (MADIS; Miller et al. 2007; Helms et al. 2009). These hourly gauge accumulations are quality controlled through a scheme described by Qi et al. (2016) with modifications outlined by Martinaitis et al. (2018). Approximately $85 \%$ of gauge observations per hour are deemed usable for MRMS QPE generation through this scheme.

Hourly radar-based accumulations are locally bias corrected using these quality controlled hourly gauge observations through an inverse distance weighting (IDW) scheme that varies the radius of the interpolation weight each hour through a cross validation methodology to minimize interpolation errors (Zhang et al. 2016). The correction of biases within the radar-based accumulations in MRMS using gauge observations improves precipitation accuracy across the CONUS in areas of radar coverage (Zhang et al. 2016). The Mountain Mapper QPE scheme in MRMS utilizes IDW with a fixed radius of $200 \mathrm{~km}$ (Zhang et al. 2016). These gauge observations are critical to the Mountain Mapper QPE generation, especially in areas of complex terrain that are not sampled well by radars. The interpolation of gauge observations with precipitation climatologies in mountainous areas have provided greater precipitation accuracy in complex terrain (Schaake et al. 2004; Zhang et al. 2014).

Hourly NWP QPFs are the only non-MRMS source utilized in the study. Integrated into the scheme are the 1-h forecasts from the operational HRRR version 2 (hereinafter denoted as HRRRv2) at a 3-km horizontal resolution. HRRRv2 model configurations can be found in Lawson et al. (2018). The HRRRv2 QPFs are mapped to the MRMS 1-km Cartesian grid for spatial continuity among precipitation inputs. Satellite-based QPE from the Self-Calibrating Multivariate Precipitation Retrieval (SCaMPR; Kuligowski 2002; Kuligowski et al. 2016) algorithm using the latest Geostationary Operational Environmental Satellite (GOES) information from GOES-16 was considered for this study due to its high spatiotemporal resolution and full coverage over the CONUS with little product latency; however, analysis of SCaMPR QPEs showed that the SCaMPR algorithm struggled with capturing the proper delineation of precipitation coverage and the magnitude of precipitation across various precipitation event types (e.g., Fig. 2). The study presented here does not include a satellite QPE component in the multisensor scheme.

\section{b. Data limitations}

Each precipitation input for MSQPE has its own inherent set of limitations. Observations recorded by gauges may not always be representative of reality. The gauge orifice can be subject to blockages that can underestimate or even prevent the measuring of precipitation 

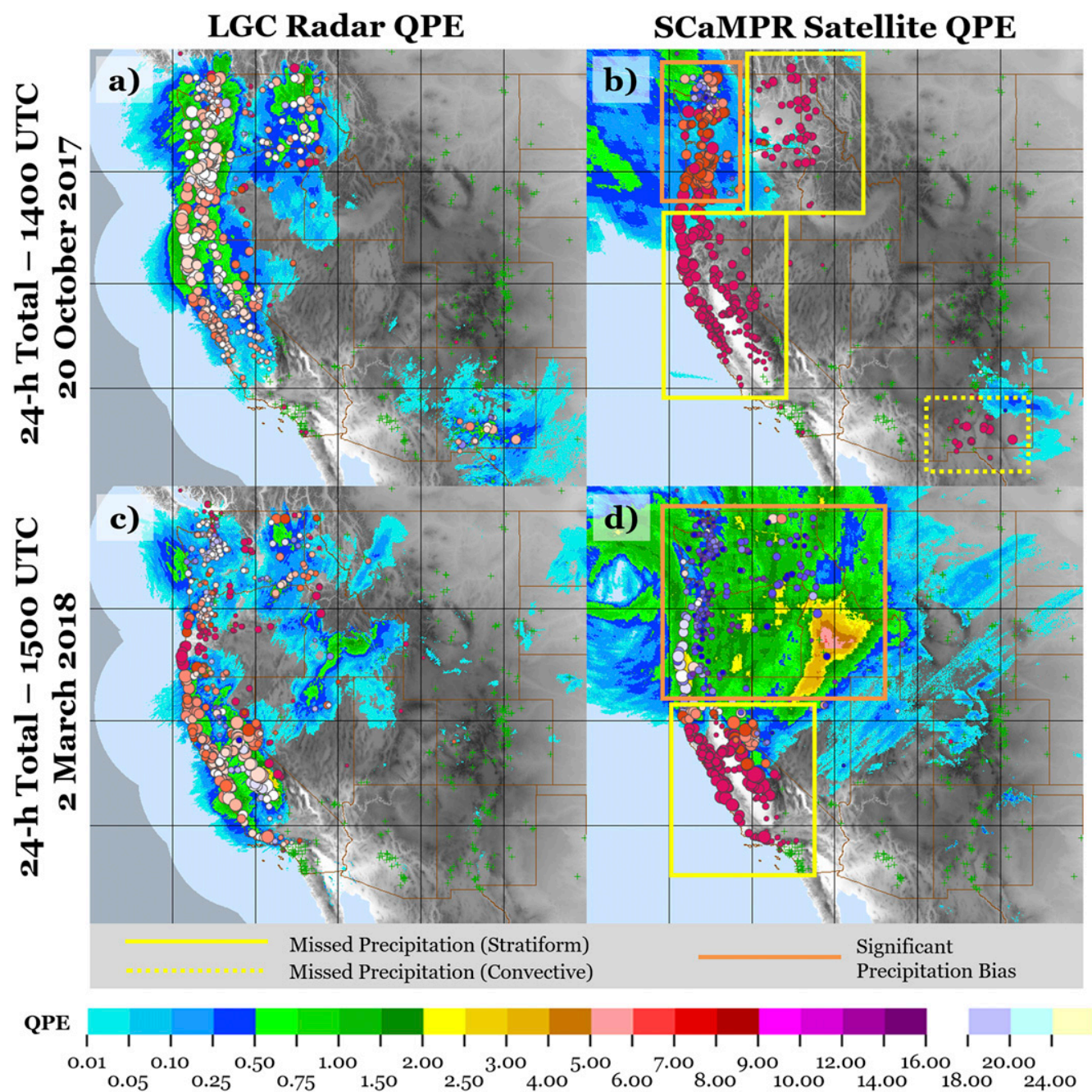

Bias Ratio
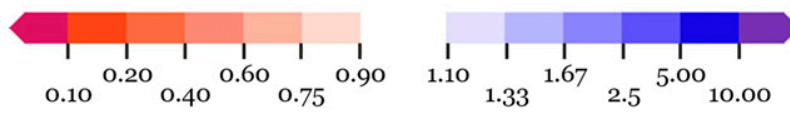

QPE/Gauge

FIG. 2. Comparison of MRMS (a),(c) LGC radar QPE to (b),(d) SCaMPR satellite QPE for the 24-h accumulation period ending (top) 1400 UTC 20 Oct 2017 and (bottom) 1500 UTC 2 Mar 2018. All accumulations shown are compared to CoCoRaHS gauge observations with coloring denoting the bias of the gridded QPE to the recorded gauge observation (bubble plots). Yellow boxes denote areas where the SCaMPR satellite QPE missed stratiform (solid line) and convective (dashed line) precipitation events. Orange boxes denote areas where there were significant biases in the SCaMPR satellite QPE value compared to the CoCoRaHS gauge observations.

(Sevruk 2005; Sieck et al. 2007). Instrumentation and siting issues can result in systematic biases and improper calibration (Groisman and Legates 1994; Steiner et al. 1999; Kondragunta and Shrestha 2006; Sieck et al. 2007). Strong surface winds can lead to precipitation undercatch, and the degree of wind undercatch varies based on precipitation type and gauge shielding characteristics (e.g., Larson and Peck 1974; Wilson and Brandes 1979; Yang et al. 1998). Rain gauges have also been shown to have challenges with accurate liquidequivalent accumulations (Metcalfe and Goodison 1992;
Groisman and Legates 1994; Goodison et al. 1998; Rasmussen et al. 2012) and commonly report zero precipitation or inaccurate nonzero observations from blockages of the gauge orifice during winter events (Martinaitis et al. 2015).

Radar-derived QPEs are subject to error through improper calibration or the utilization of unrepresentative reflectivity-rain rate $(Z-R)$ and reflectivity-snow rate $(Z-S)$ relationships (e.g., Joss and Waldvogel 1969; Wilson and Brandes 1979; Zawadzki 1984; Austin 1987; Smith et al. 1996; Young et al. 1999). Radar-derived 

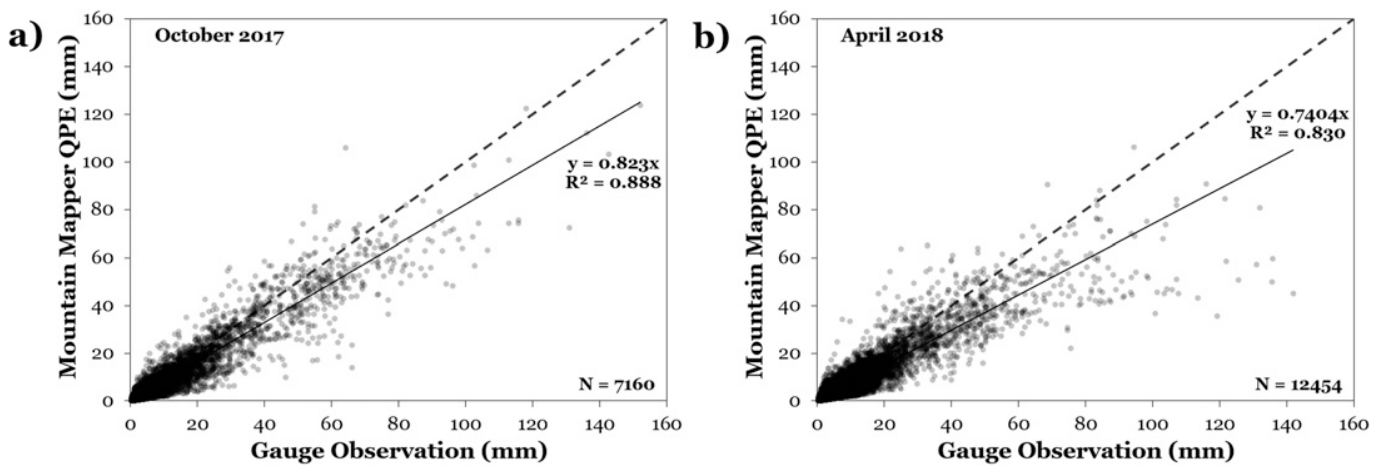

FIG. 3. Analysis of MRMS Mountain Mapper QPE compared to independent CoCoRaHS gauge observations over the western CONUS (i.e., west of $100^{\circ} \mathrm{W}$ longitude) for the month of (a) October 2017 and (b) April 2018. The dashed line represents the one-to-one line. The solid line represents the linear best-fit line with the associated equation and coefficient of determination $\left(R^{2}\right)$. The gauge vs Mountain Mapper QPE sample size $(N)$ is provided in the bottom-right corner and consists of the number of nonzero pairings for that particular month.

QPEs based on dual-polarization variables are dependent upon the calibration of both the horizontal and vertical channels that influence some of the dualpolarization products. Other challenges include the appropriateness of the applied precipitation rate relationships and the limitations of dual-polarization variables for different precipitation types. Sampling through the melting layer can result in erroneously high precipitation values (Smith 1986). The lowest elevation scans can be contaminated by ground clutter and nonmeteorological echoes (e.g., Young et al. 1999; Harrison et al. 2000); furthermore, nonuniform beam filling and larger sample sizes with increasing range from radar can result in nonrepresentative reflectivity data or create improper biases in precipitation (Rogers 1971; Rosenfeld et al. 1992, 1993). The aforementioned limitations of gauge observations can apply inaccurate bias corrections of radar-derived QPEs (Seo and Breidenbach 2002; Martinaitis et al. 2015).

The limitations of gauge observations and the inability to efficiently quality control observations in regions not adequately sampled by radars can also influence the quality of the Mountain Mapper QPE. The challenges of winter precipitation with rain gauges can greatly reduce the number of accurate observations; thus, the lack of observations would not allow for a proper depiction of liquid-equivalent accumulations in mountainous regions. MRMS Mountain Mapper QPEs systematically underestimates precipitation when compared to independent daily gauge observations (e.g., Martinaitis et al. 2014). Bias analyses over the western CONUS for October 2017 and April 2018 when synoptically driven rain events were prevalent consistently show an underestimation bias of approximately $20 \%$ (Fig. 3). The
MRMS IDW methodology for Mountain Mapper QPE also allows for a large interpolation of a single nonzero gauge observation in a gauge-sparse region, including that of localized convective storms with large accumulation gradients. The depicted areal extent of nonzero precipitation through the $200-\mathrm{km}$ interpolation radius is not representative of the true precipitation coverage, more notably for hourly accumulations $<0.508 \mathrm{~mm}$ (0.02 in.; e.g., Fig. 4).

NWP model QPF challenges can be driven by uncertainties from model initialization (e.g., Lin et al. 2005) and performance with radar data assimilation (e.g., Pinto et al. 2015). Duda et al. (2014) summarized other NWP challenges and ensemble forecasting that can create errors in QPFs, including uncertainties in initial conditions, systematic model error, and sensitivities to microphysics and boundary layer parameterizations. Similar challenges and uncertainties that impact modelderived QPFs can also influence other NWP parameters utilized within the MSQPE scheme. Upstream convection has also been shown to influence model biases of downstream convection based on storm motion and the subsequent impacts on moisture transport and the low-level jet (Mahoney and Lackmann 2007). Modelcalculated precipitation rates, including the prediction of hydrometeor mixing ratios and fall speeds in convective-allowing models, also have uncertainty and limitations that can impact the resulting precipitation forecast.

\section{c. Defining radar coverage gaps}

It is important to understand where radar-derived precipitation might not be optimal and would require other sources to improve precipitation coverage and 


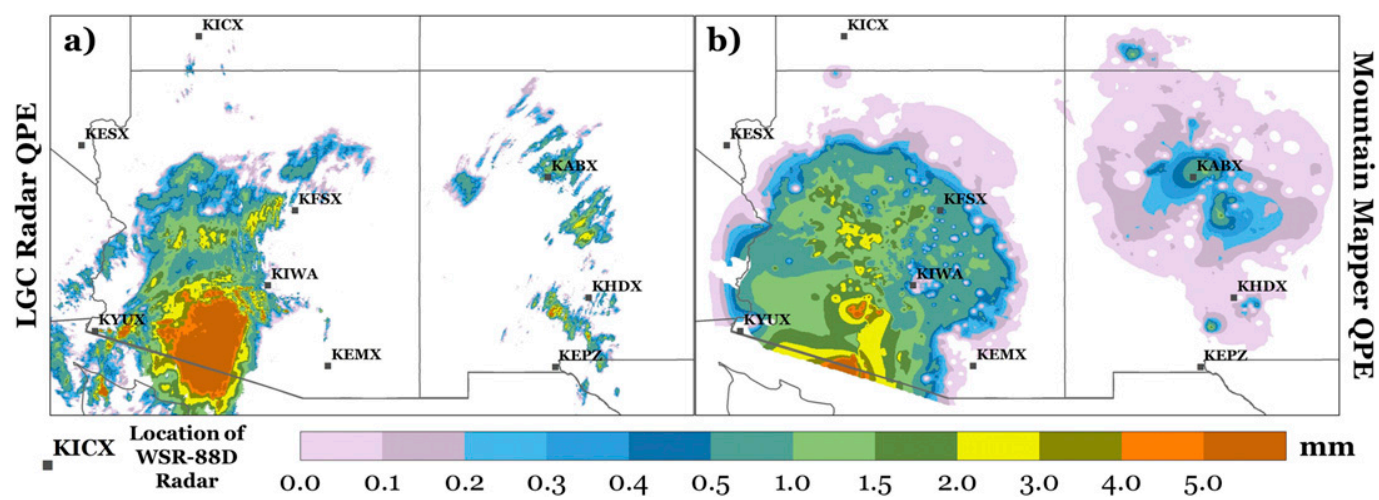

FIG. 4. Comparison of 1-h (a) LGC radar QPE and (b) Mountain Mapper QPE for the period ending 0800 UTC2 Oct 2018. The lower precipitation accumulations were emphasized in the color scale to demonstrate the differences between a radar-based approach (LGC radar QPE) and the gauge-only Mountain Mapper QPE with large spatial interpolations.

accuracy. The MRMS system computes a radar quality index (RQI) that serves as a proxy for radar coverage and data uncertainty (Zhang et al. 2012a). The RQI is defined by radar beam blockage and height characteristics,

$$
\mathrm{RQI}=\mathrm{RQI}_{\mathrm{blk}} \times \mathrm{RQI}_{\mathrm{hgt}},
$$

with two primary components: radar beam blockage $\mathrm{RQI}_{\mathrm{blk}}$ and radar beam height characteristics $\mathrm{RQI}_{\text {hgt }}$, which accounts for height above radar level (ARL) and the beam location with respect to the freezinglevel height and brightband thickness. The RQI is calculated on a unitless scale from 0.0 to 1.0, where a value of 1.0 represents data with the highest potential quality.

Adjustments to the Zhang et al. (2012a) logic were made for this study to better define radar coverage. $\mathrm{RQI}_{\text {blk }}$ was modified to accommodate for beam blockage (blk) up to $60 \%$ for a beam that is at least $10 \mathrm{~m}$ AGL:

$$
\mathrm{RQI}_{\mathrm{blk}}= \begin{cases}1 ; & \mathrm{blk}<0.1 \\ 1-\frac{\mathrm{blk}-0.1}{0.5} ; & 0.1 \leq \mathrm{blk} \leq 0.6\end{cases}
$$

A beam that has blk $>60 \%$ is not considered in the generation of seamless reflectivity maps in MRMS based on criteria used to develop hybrid scan reflectivities in MRMS; thus, the next elevation angle with blk $\leq 60 \%$ is considered in the calculation. The RQI ${ }_{\text {hgt }}$ logic is dependent on the radar beam location with respect to the freezing-level height $H_{0 \mathrm{C}}$ and a reference height $H_{D}$ where radar observations become less correlated with surface precipitation. Height $H_{D}$ is $1000 \mathrm{~m}$ for the MRMS CONUS domain. $\mathrm{RQI}_{\mathrm{hgt}}$ for areas where $H_{0 \mathrm{C}}>H_{D}$ is defined as

$$
\mathrm{RQI}_{\mathrm{hgt}}=\left\{\begin{array}{ll}
1 ; & h<H_{D} \\
\exp \left[-\frac{\left(h-H_{D}\right)^{2}}{H_{1}^{2}}\right] ; & H_{D} \leq h \leq H_{0 \mathrm{C}} \\
\exp \left[-\frac{\left(h-H_{D}\right)^{2}}{H_{1,2}^{2}}\right] ; & H_{0 \mathrm{C}}<h \leq H_{0 \mathrm{C}}+\Delta H \\
\exp \left[-\frac{\left(h-H_{D}\right)^{2}}{H_{2}^{2}}\right] ; & h>H_{0 \mathrm{C}}+\Delta H
\end{array},\right.
$$

where $h$ is the adjusted top beam height (m AGL), $H_{1}$ is a height-scale factor in rain $(4000 \mathrm{~m}), H_{2}$ is a heightscale factor in snow $(3000 \mathrm{~m}), \Delta H$ is a transition zone defaulted at $800 \mathrm{~m}$ for the height-scale transition from $H_{1}$ to $H_{2}$, and $H_{1,2}$ is a height scale varying linearly from $H_{1}$ to $H_{2}$ across the transition zone. Heights $H_{1}$ and $H_{2}$ are defined to vary the reduction of RQI within the two different precipitation regimes. $\mathrm{RQI}_{\mathrm{hgt}}$ for areas where $0<H_{0 \mathrm{C}} \leq H_{D}$ is defined as

$$
\mathrm{RQI}_{\mathrm{hgt}}= \begin{cases}1 ; & h<H_{0 \mathrm{C}} \\ \exp \left[-\frac{\left(h-H_{0 \mathrm{C}}\right)^{2}}{H_{2}^{2}}\right] ; & h \geq H_{0 \mathrm{C}} .\end{cases}
$$

$\mathrm{RQI}_{\mathrm{hgt}}$ for areas where $H_{0 \mathrm{C}} \leq 0$ is defined as

$$
\mathrm{RQI}_{\mathrm{hgt}}=\exp \left(-\frac{h^{2}}{H_{2}^{2}}\right) \text {. }
$$

The height parameters were selected subjectively based on evaluations of MRMS radar QPEs (Chen et al. 2013) 

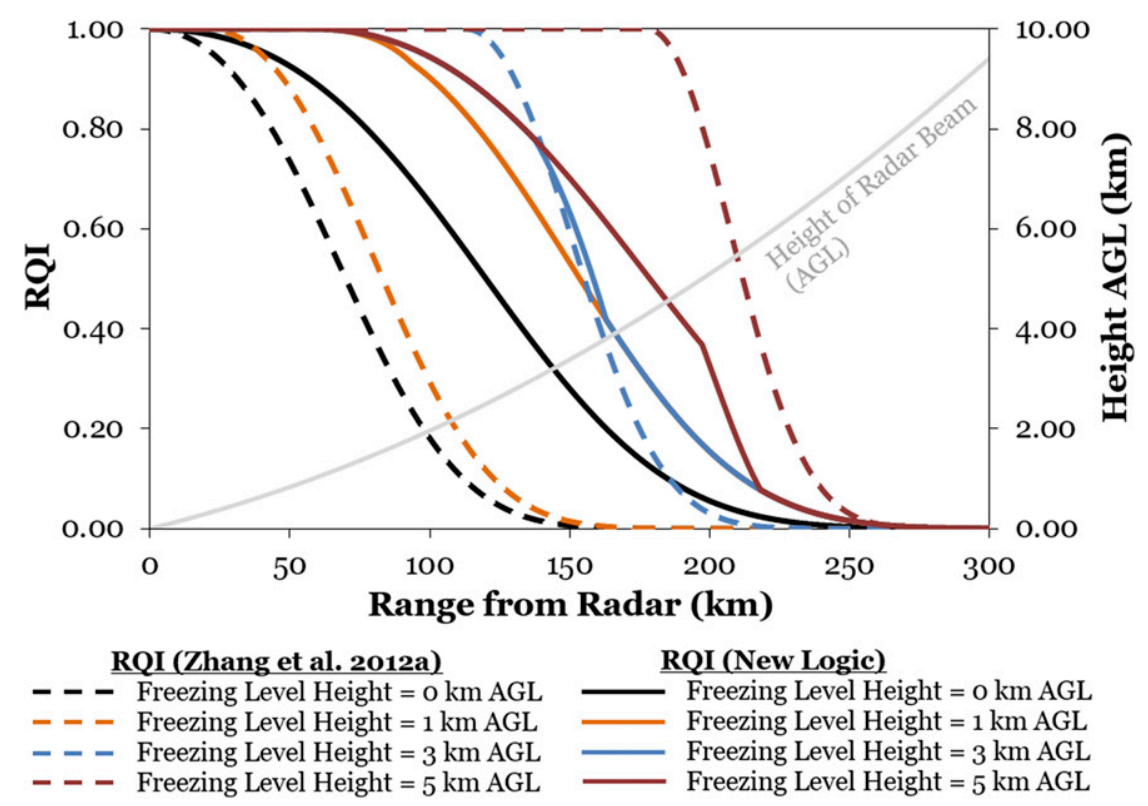

FIG. 5. RQI value calculations with varying freezing-level heights for a radar beam up to a range of $300 \mathrm{~km}$ across a homogeneous surface using the Zhang et al. (2012a) scheme (dashed lines) and the logic presented in this study (solid lines).

to reflect the relative radar QPE quality degradation as a function of range via beam spreading and beam overshooting of microphysical processes that play a major role in identifying near-surface precipitation intensity.

Beam height calculations changed from ARL to AGL to account for variations in beam height over complex terrain. The mathematical changes to RQI resulted in a more consistent performance based on the improved variables to account for sampling degradation with increased range from radar and height AGL along with adjustments relating to the application of freezing-level height influences (Fig. 5). The precision of the final RQI output was increased from 0.1 to 0.01 to prevent potential discontinuities during the blending of precipitation sources. These cumulative RQI improvements allow for a better representation of where optimal radar coverage exists while mitigating artifacts and discontinuities (Fig. 6).

\section{Multisensor gap-filling scheme}

\section{a. Blending logic}

The physical blending of multiple precipitation sources utilizes radar coverage, atmospheric conditions, and orography based on the various strengths of each precipitation input (Fig. 7). The MSQPE foundationally utilizes the equation from Zhang et al. (2014) redefined as the following:

$$
\mathrm{MSQPE}=\frac{w_{g} Q_{\mathrm{GAP}}+\left(1-w_{g}\right) w_{r} Q_{\mathrm{LGC}}}{w_{g}+\left(1-w_{g}\right) w_{r}} .
$$

The LGC radar QPE $\left(Q_{\mathrm{LGC}}\right)$ is the primary precipitation input and weighted by the variable $w_{r}$. The amalgamation of the remaining precipitation sources is handled by the gap-filling QPE $\left(Q_{\mathrm{GAP}}\right)$ weighted by the variable $w_{g}$. The $Q_{\mathrm{GAP}}$ is calculated using the following logic:

$$
Q_{\mathrm{GAP}}=Q_{\mathrm{NWP}}\left(1-w_{m}\right)+s w_{m} Q_{\mathrm{MM}} .
$$

Integration of gap-filling HRRRv2 model 1-h QPF $\left(Q_{\mathrm{NWP}}\right)$ and the MRMS Mountain Mapper QPE $\left(Q_{\mathrm{MM}}\right)$ utilizes the Mountain Mapper weighting function $w_{m}$ :

$$
w_{m}=w_{s} \times w_{t w b} \times\left(1-w_{f}\right) \times \alpha .
$$

The static weighting variable $w_{s}$ is defined by a gridded slope field based on topographic steepness and allows for $Q_{\mathrm{MM}}$ to be applied over complex terrain only. Grid cells with a slope $\geq 5.0^{\circ}$ have a value of 1.00 , and a buffer of $20 \mathrm{~km}$ is applied around these grid cells with $w_{s}$ reducing linearly by $0.05 \mathrm{~km}^{-1}$ (Fig. 8).

The weighting variable $w_{\text {twb }}$ utilizes the HRRRv2 model surface wet-bulb temperature $T_{\text {wb }}$ to delineate areas of frozen precipitation versus rain to restrict the use of $Q_{\mathrm{MM}}$ in winter precipitation due to limitations of recording accurate liquid-equivalent accumulations. Application of the surface $T_{\mathrm{wb}}$ accounts for the 


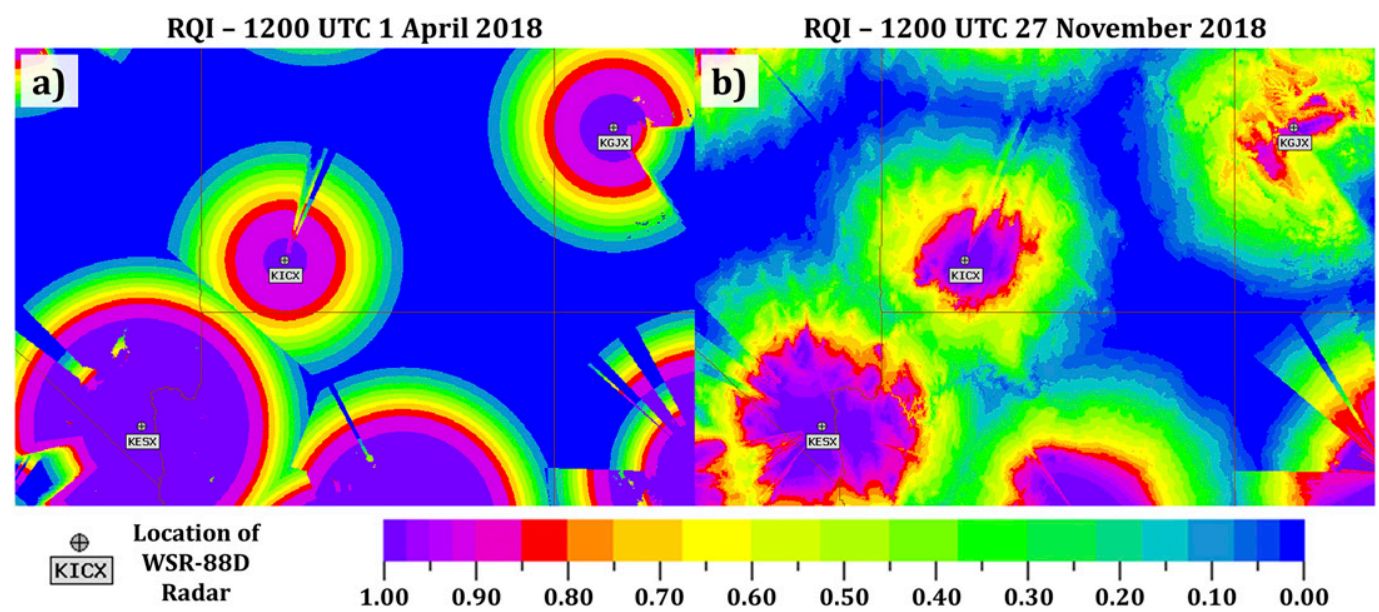

FIG. 6. RQI product (a) calculated from the Zhang et al. (2012a) scheme at 1200 UTC 1 Apr 2018 and (b) calculated from the modified scheme at 1200 UTC 27 Nov 2018. The environments influencing RQI in both (a) and (b) are similar.

occurrence of frozen precipitation within environments defined by above-freezing ambient temperatures and nonsaturated relative humidity values (e.g., Matsuo and Sasyo 1981). A threshold surface $T_{\mathrm{wb}}$ of $0.00^{\circ} \mathrm{C}$ is used based on the work by Martinaitis et al. (2015) with a linear transition defined by

$$
w_{\mathrm{twb}}= \begin{cases}1.00 ; & T_{\mathrm{wb}} \geq 2.00 \\ \frac{T_{\mathrm{wb}}}{2} ; & 0.00<T_{\mathrm{wb}}<2.00 . \\ 0.00 ; & T_{\mathrm{wb}} \leq 0.00\end{cases}
$$

The blending of $Q_{\mathrm{NWP}}$ and $Q_{\mathrm{MM}}$ is also characterized by a delineation of warmer and cooler atmospheric environments based on the freezing-level height $f$ in meters AGL to limit the use of $Q_{\mathrm{MM}}$ in convective precipitation using the weighting function $w_{f}$, which is defined as

$$
w_{f}= \begin{cases}1.00 ; & f \geq 3000 \\ \frac{f-1750}{1250} ; & 1750<f<3000 . \\ 0.00 ; & f \leq 1750\end{cases}
$$

The use of $f$ and its linear blending value range for defining atmospheric environments for stratiform and convective precipitation properties is modified from the surface precipitation type classification decision

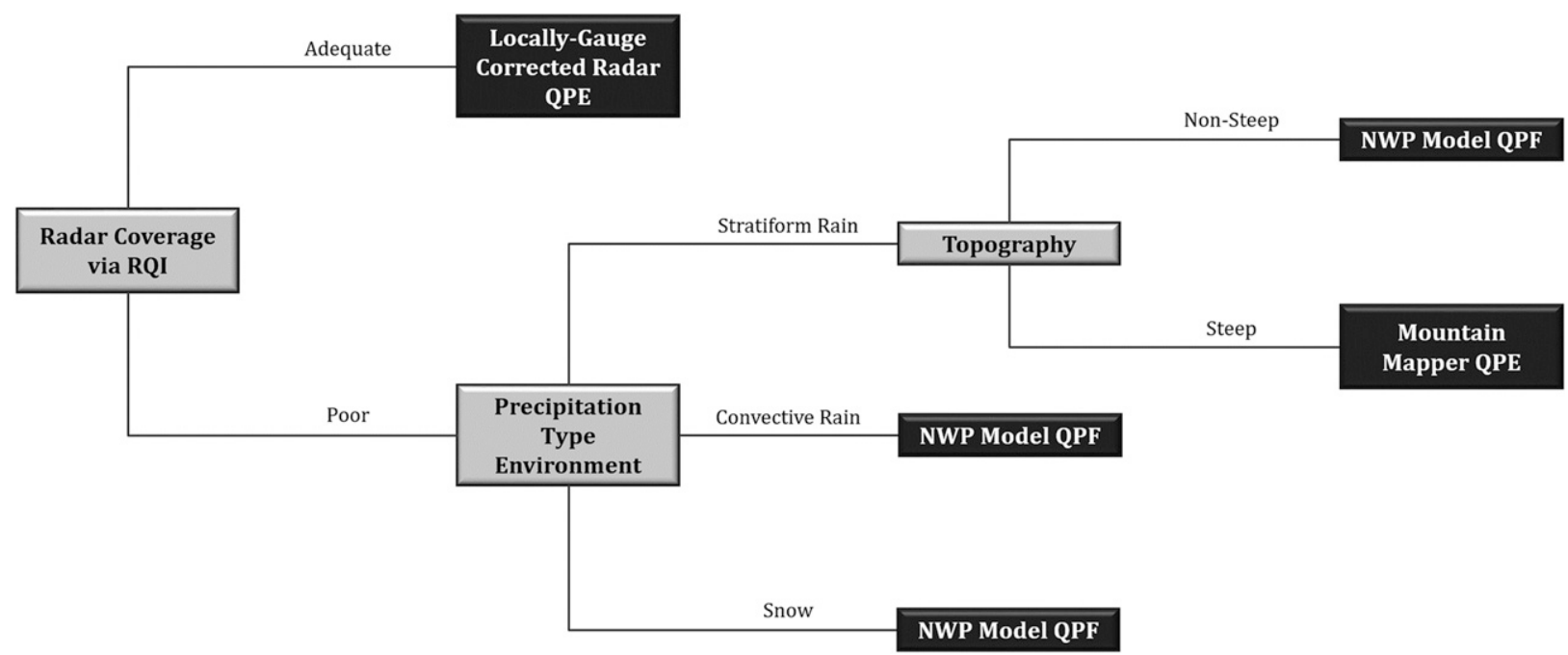

FIG. 7. Decision tree on the application of the three input QPE/QPF fields into the MSQPE product. 


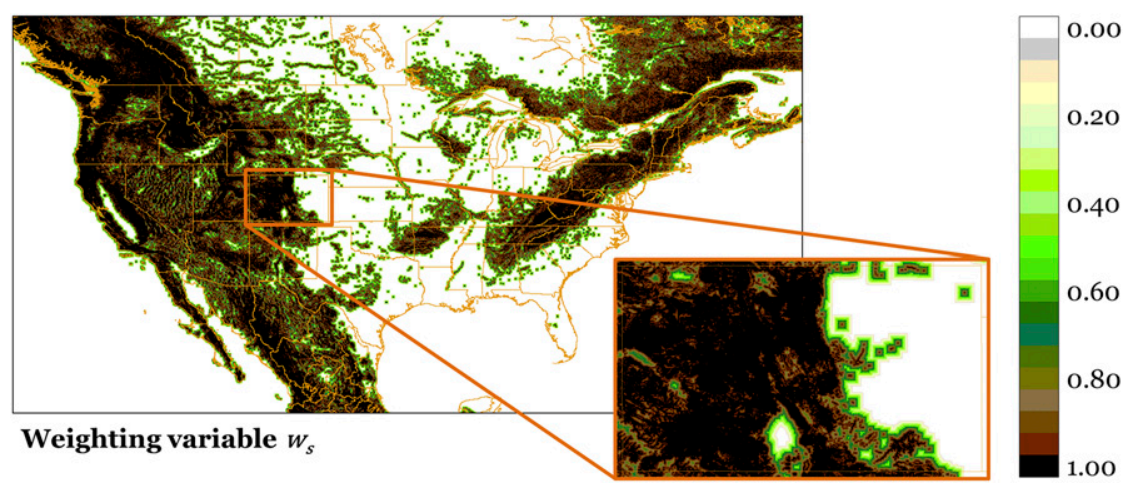

FIG. 8. Coverage of weighting variable $w_{s}$ over the MRMS CONUS domain to influence use of $Q_{\mathrm{MM}}$ in MSQPE generation. Inset shows detail of $w_{s}$ over Colorado.

tree for identifying convective precipitation (Zhang et al. 2016) based upon evaluations of precipitation events during the MSQPE product development.

The scaling factor $s$ in Eq. (7) and the variable $\alpha$ in Eq. (8) address some $Q_{\mathrm{MM}}$ deficiencies. The persistent underestimation bias of $Q_{\mathrm{MM}}$ is corrected through the scaling factor $s$ set to a constant value of 1.2035 using a linear best-fit equation based $Q_{\mathrm{MM}}$ comparisons to independent gauge data (e.g., Fig. 3). The variable $\alpha$ prevents the use of nonrealistic light precipitation coverage (e.g., Fig. 4) via the following logic:

$\alpha= \begin{cases}1.00 ; & \left(s \times Q_{\mathrm{MM}}\right) \geq 2.032 \\ \frac{\left(s \times Q_{\mathrm{MM}}\right)-0.508}{1.254} ; & 0.508<\left(s \times Q_{\mathrm{MM}}\right)<2.032 . \\ 0.00 ; & \left(s \times Q_{M M}\right) \leq 0.508\end{cases}$

The values of $0.508 \mathrm{~mm}(0.02 \mathrm{in}$.) and $2.032 \mathrm{~mm}(0.08 \mathrm{in}$.) for the linear blending of $Q_{\mathrm{MM}}$ are derived from extensive internal studies on the interpolation of $Q_{\mathrm{MM}}$ values.

The weighting functions $w_{r}$ and $w_{g}$ in Eq. (6) balance the combination of $Q_{\mathrm{LGC}}$ and $Q_{\mathrm{GAP}}$. The weighting function $w_{r}$ for $Q_{\mathrm{LGC}}$ is based on the MRMS RQI product as the proxy for radar coverage. The extent of $Q_{\mathrm{LGC}}$ coverage is dynamically altered based on atmospheric parameters characterizing warm and cool precipitation environments via $w_{f}$. The weighting of $Q_{\mathrm{LGC}}$ via $w_{r}$ is defined as

$w_{r}= \begin{cases}1.00 ; & \mathrm{RQI} \geq\left(1.00-0.70 w_{f}\right) \\ y ; & \left(0.60-0.60 w_{f}\right)<\mathrm{RQI}<\left(1.00-0.70 w_{f}\right) . \\ 0.00 ; & \mathrm{RQI} \leq\left(0.60-0.60 w_{f}\right)\end{cases}$

The full use of $Q_{\text {LGC }}$ for stratiform rain and snow environments is only when RQI $=1.00$ and then reduces in contribution until RQI $=0.60$. The influence of $Q_{\mathrm{LGC}}$ is much greater in convective environments, where $Q_{\text {LGC }}$ is fully utilized in the RQI range of $0.30-1.00$ with reduced $Q_{\mathrm{LGC}}$ contributions until RQI $=0.00$. These values were defined based on extensive analysis of and contrasting of shallow stratiform precipitation events to convective events. The contribution of $Q_{\mathrm{LGC}}$ within the dynamic RQI range bounded by the incorporation of $w_{f}$ is calculated through the cubic polynomial function $y$ :

$$
y=\left(n_{3} x^{3}\right)+\left(n_{2} x^{2}\right)+\left(n_{1} x\right)+n_{0} .
$$

The $n$ variables in Eq. (13) are quadratic functions dynamically based on $w_{f}$ and are defined by the following:

$$
\begin{aligned}
& n_{3}=39.904 w_{f}^{2}-40.464 w_{f}+0, \\
& n_{2}=-59.075 w_{f}^{2}+53.614 w_{f}+3.3333, \\
& n_{1}=18.168 w_{f}^{2}-11.674 w_{f}-2.8333,
\end{aligned}
$$

and

$$
n_{0}=w_{f}^{2}-1.5 w_{f}+0.5 \text {. }
$$

The weighting of $Q_{\mathrm{GAP}}$ via $w_{g}$ also relies upon RQI and $w_{f}$; however, it also contains logic to increase the weight of $Q_{\mathrm{LGC}}$ at gauge observations within a certain range of radar influence. The calculations for $w_{g}$ utilize the following logic:

$$
w_{g}= \begin{cases}0.00 ; & \mathrm{RQI} \geq\left(1.00-0.70 w_{f}\right) \\ g_{i} ; & \left(0.60-0.60 w_{f}\right)<\mathrm{RQI}<\left(1.00-0.70 w_{f}\right) \\ \beta ; & \mathrm{RQI} \leq\left(0.60-0.60 w_{f}\right)\end{cases}
$$

A nonzero value of $w_{g}$ is based on the gauge influence function $g_{i}$ and a background weighting function $\beta$. The function $g_{i}$ allows for greater weight of $Q_{\mathrm{LGC}}$ near gauge 
locations to locally retain the gauge-corrected radarbased spatial representation of precipitation by reducing the influence of $Q_{\mathrm{GAP}}$ via

$$
g_{i}= \begin{cases}\beta \times \sin \left(\frac{\pi d}{2 R_{i}}\right) ; & d \leq R_{i} \\ \beta ; & d>R_{i}\end{cases}
$$

where $R_{i}$ is the radius of influence at a fixed value of $20 \mathrm{~km}$ and $d$ is the distance of a grid cell from the nearest gauge observation. The grid cell containing the gauge observation will utilize $Q_{\mathrm{LGC}}$ while a sine function using $\beta$ creates a seamless transition between $Q_{\mathrm{LGC}}$ at $d=0$ and the weighted combination of $Q_{\mathrm{GAP}}$ and $Q_{\mathrm{LGC}}$ when $\beta \neq 0$ and $d \leq R_{i}$.

Grid cells outside of $R_{i}$ will rely solely on the background weighting function $\beta$, which dynamically changes in a similar manner to $w_{g}$ in order to vary the contribution of $Q_{\mathrm{GAP}}$ for warmer and cooler atmospheric environments. The background weighting function $\beta$ utilized in $w_{g}$ and $g_{i}$ is characterized by RQI and $w_{f}$ and is defined as

$\beta= \begin{cases}0.00 ; & \mathrm{RQI} \geq\left(1.00-0.70 w_{f}\right) \\ \beta_{n z} ; & \left(0.60-0.60 w_{f}\right)<\mathrm{RQI}<\left(1.00-0.70 w_{f}\right), \\ \beta_{\max } ; & \mathrm{RQI} \leq\left(0.60-0.60 w_{f}\right)\end{cases}$

where

$$
\begin{aligned}
\beta_{n z}= & \left\{\beta_{\max }-\left[\frac{\mathrm{RQI}-\left(0.60-0.60 w_{f}\right)}{2+3 w_{f}}\right]\right\} \\
& \times\left[\frac{\left(1.00-0.70 w_{f}\right)-\mathrm{RQI}}{\left(1.00-0.70 w_{f}\right)-\left(0.60-0.60 w_{f}\right)}\right],
\end{aligned}
$$

and

$$
\beta_{\max }=0.50-0.30 w_{f}
$$

The combination of $w_{r}$ and $w_{g}$ from Eq. (6) defines the percent contribution of $Q_{\mathrm{LGC}}$ and $Q_{\mathrm{GAP}}$ at a grid cell (Fig. 9). The $Q_{\mathrm{GAP}}$ and $Q_{\mathrm{LGC}}$ would have an equal contribution for shallow stratiform rain and snow in cooler environments (i.e., when $w_{f}=0.00$ ) at $\mathrm{RQI} \approx 0.75$ and for convective regimes $\left(w_{f}=1.00\right)$ at $\mathrm{RQI} \approx 0.05$. The resulting MSQPE undergoes one last check before producing the gridded output. The blending of precipitation inputs can generate areas of light precipitation artifacts. Hourly precipitation values $<0.2 \mathrm{~mm}$ are reset to $0.0 \mathrm{~mm}$ to mitigate instances of nonzero

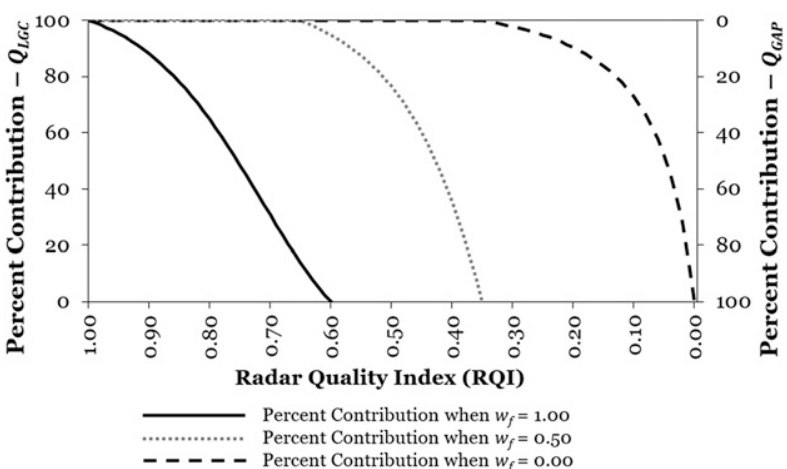

FIG. 9. The percent contribution of $Q_{\mathrm{LGC}}$ and $Q_{\mathrm{GAP}}$ based the combination of $w_{r}$ and $w_{g}$ beyond the $R_{i}$ influence of a gauge observation. The percent contribution shown is based on RQI value and the weighting variable $w_{f}$ when $w_{f}=1.00$ (solid line), 0.50 (short-dashed line), and 0.00 (long-dashed line).

MSQPE values being collocated with hourly gauges observing no precipitation.

\section{b. Product timing}

The MRMS system ingest of gauge networks captures approximately $90 \%$ of all observations at $70 \mathrm{~min}$ past valid time. The data latency of gauge observations combined with the computation time to generate both $Q_{\mathrm{LGC}}$ and $Q_{\mathrm{MM}}$ along with the final MSQPE product results in an approximately 85-min latency from valid time for MSQPE. This makes MSQPE applicable for hydrologic model forcing along with water resourcing and climatological assessments but not for flash flood detection and warning decisions. Rate-driven events and quick basin response times would require the use of a radar-only QPE (in areas where radar coverage is provided) that have a data latency of $<90$ s to help facilitate flash flood warning decision making.

\section{Evaluation methodology}

Hourly MSQPE products are created for the CONUS at the top of the hour and accumulated to 24-h totals. Performance evaluations of the MSQPE product were then conducted on 43 event days west of $100^{\circ} \mathrm{W}$ longitude and 25 event days east of $100^{\circ} \mathrm{W}$ longitude (Table 1). The three input precipitation sources and the final MSQPE product were compared against independent Community Collaborative Rain, Hail and Snow (CoCoRaHS) network daily gauge observations (Cifelli et al. 2005). The comparison between CoCoRaHS gauges and the 24 -h precipitation product accumulations were conducted over a 3-h period. Events over the western CONUS were evaluated over a period from 1400 to 1600 UTC in standard time and from 1300 to 
TABLE 1. List of the 68 total cases utilized to evaluate the MSQPE product separated by their domain areas over the CONUS. The western CONUS events were focused on the area west of $100^{\circ} \mathrm{W}$ longitude, and the eastern CONUS events were focused on the area east of $100^{\circ} \mathrm{W}$ longitude. The dates listed are the event days of the ending 24-h period. The range of hours listed represent the hourly periods where gridded precipitation products were compared to CoCoRaHS observations, which were available during these hourly ranges due to variations in reporting times.

\begin{tabular}{lcccc}
\hline \hline Domain & Year & Month & Dates & Hours evaluated (UTC) \\
\hline Western CONUS & 2017 & 10 & $8-9,11-13,19-21$ & $1300-1500$ \\
& & 11 & $13-18,21-24,26-28$ & $1300-1500$ \\
& & 11 & $17-18,21,23-24$ & $1400-1600$ \\
& 2018 & 12 & $4-6,16-20$ & $1400-1600$ \\
& & $2-3$ & 21 & $1400-1600$ \\
Eastern CONUS & & $1400-1600$ & $1300-1500$ \\
& 2018 & 6 & $6,9-10,25-27$ & $1300-1500$ \\
& 2019 & 12 & $2-3$ & $1200-1400$ \\
& & 3 & $12-13,20,25,27-28$ & $1200-1400$ \\
& & $2-4$ & $1200-1400$ \\
\end{tabular}

1500 UTC in daylight saving time. Eastern CONUS events were evaluated from 1200 to 1400 UTC in standard time and from 1100 to 1300 UTC in daylight saving time. This was done to utilize as many CoCoRaHS observations as possible when generally reporting at 0700 local time. CoCoRaHS gauges $> \pm 10 \mathrm{~min}$ of the top of the hour were removed to avoid potential biases from temporal differences. The authors also removed CoCoRaHS gauge observations that were deemed erroneous to prevent inaccurate results. Erroneous gauges were either extreme outliers or zero values in areas of significant precipitation (i.e., $>12.7 \mathrm{~mm}$ ) based on gridded QPEs and neighboring CoCoRaHS gauges. An average of 3-6 CoCoRaHS observations were removed per event day.

Statistical metrics used to evaluate the MSQPE performance against the four input precipitation sources include the mean bias ratio (MBR), mean error (ME), mean absolute error (MAE), and Pearson linear correlation coefficient (CC), which are defined as

$$
\begin{gathered}
\mathrm{MBR}=\frac{\sum_{i=1}^{N} R_{i}}{\sum_{i=1}^{N} G_{i}}, \\
\mathrm{ME}=\frac{\sum_{i=1}^{N}(R-G)_{i}}{N}, \\
\mathrm{MAE}=\frac{\sum_{i=1}^{N}\left|(R-G)_{i}\right|}{N},
\end{gathered}
$$

and

$$
\mathrm{CC}=\frac{\operatorname{cov}(R, G)}{\sigma_{R} \sigma_{G}} .
$$

The term $R$ represents the gridded precipitation source, $G$ represents the CoCoRaHS gauge observations, $N$ is the number of $R$ versus $G$ comparisons over the 3-h evaluation period, and $\sigma$ is the standard deviation. Pairings where both $R$ and $G$ were not reporting precipitation were not used in the statistical analyses. The removal of $G, R=0$ pairings resulted in an average of $925 R$ versus $G$ comparisons for each western CONUS event and 3500 for each eastern CONUS event. Particular attention was given to the performances between the radar-based approach (i.e., LGC radar QPE) and MSQPE to demonstrate potential improvements from utilizing a radar gap-filling methodology. All precipitation products were ranked for each event day to determine how MSQPE compared to the three gridded precipitation inputs across the different statistical measures.

The $R$ versus $G$ comparisons were also binned into three categories: the gauge and gridded precipitation product reporting precipitation $(G, R>0)$, the gauge reporting precipitation but the gridded precipitation product does not $(G>0, R=0)$, and the gridded precipitation product reporting precipitation but the gauge does not $(G=0, R>0)$. The distributions of these categories were evaluated for the precipitation inputs and final MSQPE product. Direct comparisons between the LGC radar QPE and MSQPE will quantify how the gap-filling precipitation sources reduced the $G>0$, $R=0$ instances and determine if false precipitation areas are being introduced into MSQPE. 
TABLE 2. The median, average $(\mu)$, and standard deviation $(\sigma)$ of the MBR, ME, MAE, and CC statistical measures of the three input precipitation products and the MSQPE product across the 43 evaluated cases over the western CONUS domain. The best value in each statistical category is italicized.

\begin{tabular}{|c|c|c|c|c|c|}
\hline & & LGC radar QPE & Mountain Mapper QPE & HRRRv2 1-h QPF & MSQPE \\
\hline \multirow[t]{3}{*}{ MBR } & Median & 0.747 & 0.824 & 0.963 & 0.931 \\
\hline & $\mu$ & 0.747 & 0.783 & 1.032 & 0.970 \\
\hline & $\sigma$ & 0.140 & 0.169 & 0.244 & 0.176 \\
\hline \multirow[t]{3}{*}{ ME } & Median (mm) & -1.521 & -1.047 & -0.206 & -0.449 \\
\hline & $\mu(\mathrm{mm})$ & -1.526 & -1.081 & -0.097 & -0.380 \\
\hline & $\sigma(\mathrm{mm})$ & 1.011 & 0.534 & 1.332 & 0.667 \\
\hline \multirow[t]{3}{*}{ MAE } & Median (mm) & 2.699 & 2.472 & 3.176 & 2.364 \\
\hline & $\mu(\mathrm{mm})$ & 2.780 & 2.480 & 3.453 & 2.447 \\
\hline & $\sigma(\mathrm{mm})$ & 0.990 & 0.865 & 1.554 & 0.801 \\
\hline \multirow[t]{3}{*}{$\mathrm{CC}$} & Median & 0.799 & 0.858 & 0.747 & 0.861 \\
\hline & $\mu$ & 0.752 & 0.810 & 0.732 & 0.833 \\
\hline & $\sigma$ & 0.171 & 0.128 & 0.117 & 0.090 \\
\hline
\end{tabular}

Two event days are also presented in detail. Included in the case analyses are the hourly percent contributions of each precipitation input to portray how each source influenced MSQPE. The calculation for the percent contribution of $Q_{\mathrm{LGC}}$ is

$$
\text { PERC }_{\text {LGC }}=\frac{\frac{\left(1-w_{g}\right) w_{r}}{w_{g}+\left(1-w_{g}\right) w_{r}}}{\left[\frac{\left(1-w_{g}\right) w_{r}}{w_{g}+\left(1-w_{g}\right) w_{r}}\right]+\left[\frac{w_{g}}{w_{g}+\left(1-w_{g}\right) w_{r}}\right]} .
$$

The percent contribution fields for the precipitation inputs that create $Q_{\mathrm{GAP}}$ are defined by the following:

$$
\text { PERC }_{\mathrm{MM}}=\left(1-\mathrm{PERC}_{\mathrm{LGC}}\right) w_{m},
$$

and

$$
\operatorname{PERC}_{\text {NWP }}=\left(1-\operatorname{PERC}_{\mathrm{LGC}}\right)\left(1-w_{m}\right) .
$$

\section{Overall multisensor QPE performance}

\section{a. Comparing gridded precipitation products}

Statistical measures of the 43 daily events over the western CONUS exhibited numerous improvements by MSQPE over the radar-centric LGC radar QPE (Table 2). The average overall MBR value increased from 0.747 to a more ideal 0.970. Initial underestimation biases of LGC radar QPE can be primarily attributed to the reduced radar and gauge observational density resulting in missed or underrepresented precipitation events. MSQPE produced seamless contiguous fields which mitigated the systematic underestimation bias that was a result of inadequate radar coverage. The average
ME for LGC radar QPE was reduced by $75 \%$ when applying the MSQPE scheme, and the average MAE was reduced by $12 \%$ to $2.447 \mathrm{~mm}$. The smaller decline in MAE may be influenced by biases in the LGC radar QPE and/or the gap-filling precipitation inputs having estimation biases. Large biases with the precipitation inputs can also explain the minimal reduction of the MAE standard deviation and the slight increase in the MBR standard deviation from 0.140 to 0.176 . The average overall CC values were also improved by $11 \%$ to 0.833 along with a $47 \%$ reduction of the CC standard deviation.

The MAE and CC statistics for MSQPE outperformed the three input precipitation sources, yet some of the input sources appear to have better MBR and ME statistics over MSQPE. The HRRRv2 1-h QPFs has a more ideal median MBR value as well as better median and average ME values; however, the standard deviations of the MBR and ME values for the HRRRv2 1-h QPFs are the greatest among all evaluated products (Table 2). This can be attributed to the HRRRv2 significantly overestimating precipitation magnitudes for certain events while equally underestimating precipitation for other events. The greater range of MBR values for the HRRRv2 is more clearly demonstrated through comparing the interquartile spread between the 25th and 75th percentiles (Fig. 10a). A similar pattern of results was shown for ME values. The HRRRv2 had a better average ME value by $0.243 \mathrm{~mm}$ over MSQPE, yet the standard deviation and interquartile range was more than double that of MSQPE (Fig. 10b) with reduced correlation to independent gauges compared to the other inputs and final MSQPE product (Fig. 10d). The Mountain Mapper QPE was characterized by underestimation biases along with higher ME throughout the evaluated cases; however, it did have comparable MAE and CC values to MSQPE (Figs. 10c,d). 

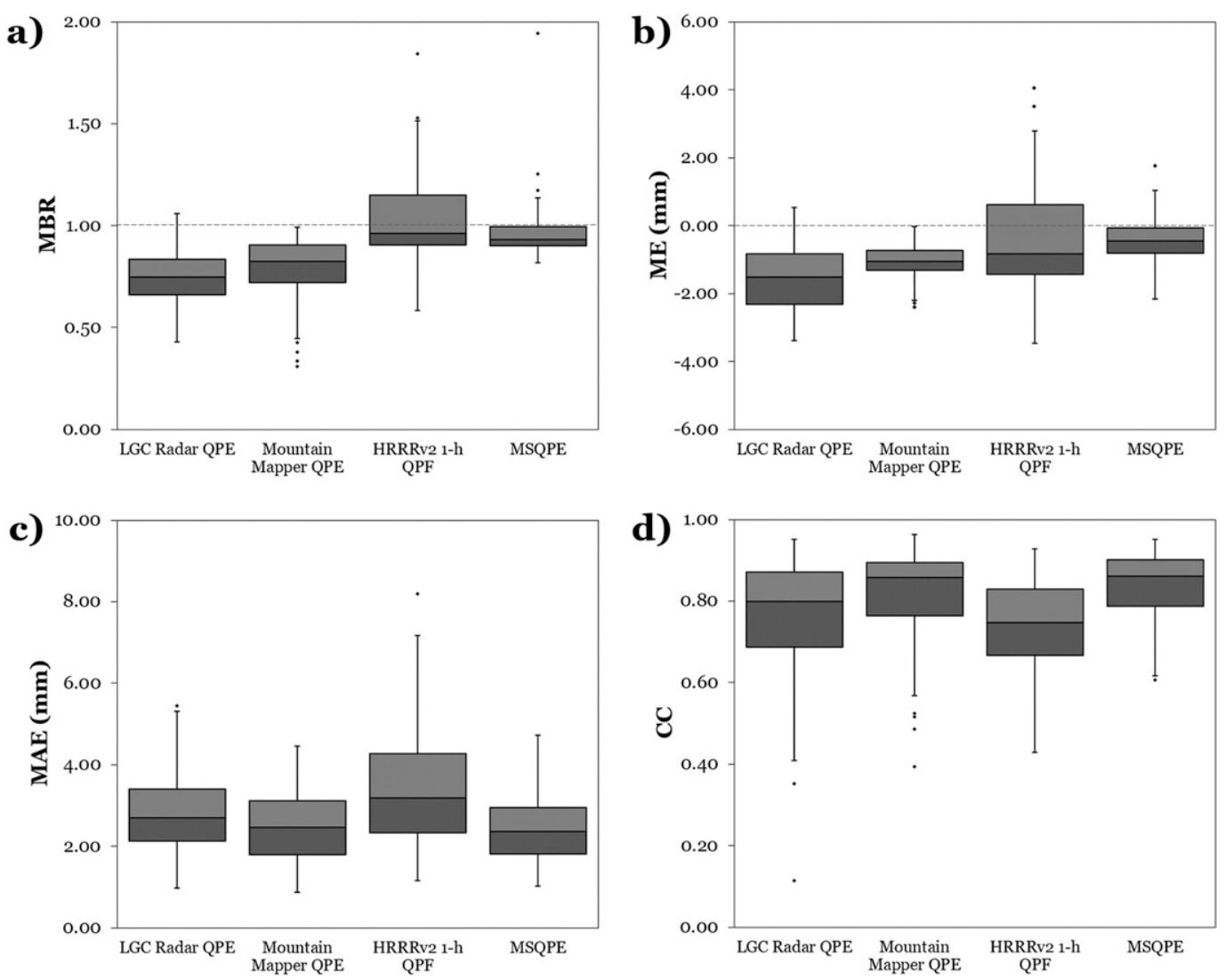

FIG. 10. Box-and-whisker plots of (a) MBR, (b) ME, (c) MAE, and (d) CC for the three input precipitation products (LGC radar QPE, Mountain Mapper QPE, and HRRRv2 1-h QPF) and the final MSQPE product across the 43 evaluated events over the western CONUS domain. The boxes extend from the $25 \%$ quartile to the $75 \%$ quartile with a horizontal line at the median values. The whiskers indicate the lowest and highest data points within 1.5 times the interquartile range of the $25 \%$ and $75 \%$ quartiles, respectively. Data points outside of the 1.5 interquartile range are represented by the solid points.

Cumulative rankings of the statistical measures further demonstrated how MSQPE was statistically superior, even though it was not the best ranked product for every case in every measure (Fig. 11). The average ranking for MSQPE was the best among the three input sources apart from MAE, where Mountain Mapper QPE had more event days with lower MAE values. MSQPE was ranked first $47.67 \%$ of the time across the four statistical categories for all event with the next closest product being Mountain Mapper QPE at 27.33\% (Table 3). MSQPE was ranked first or second $88.37 \%$ of the time and had $98.84 \%$ of all first through third rankings across the four statistical categories. Instances when MSQPE did not outperform a precipitation input were not statistically significant. MSQPE MAE values not ranked first were within $0.50 \mathrm{~mm}$ of the best ranked product for 23 of those 25 occurrences. Of the 23 events when MSQPE did not have the best CC, the difference was less than 0.06 from the best recorded value in 21 of those cases.
Similar overall statistical analysis and cumulative rankings were conducted for the eastern CONUS cases (Table 4). The average MBR of 0.922 for LGC radar QPE was improved to 0.955 using the MSQPE scheme, and the average ME value was reduced by $33 \%$ to $-0.455 \mathrm{~mm}$. The HRRRv2 1-h QPFs again displayed more ideal MBR and ME values; however, the large standard deviation in these values along with the large interquartile spread demonstrates the large variability in biases in the HRRRv2 over the eastern CONUS (Figs. 12a,b). The MSQPE product had the best average MAE and CC values, yet the differences between MSQPE and the LGC radar QPE were minimal in both the overall statistics (Table 4) and the box-and-whisker representations (Figs. 12c,d).

The cumulative rankings of the 25 eastern CONUS cases highlight some of the similarities of the LGC radar QPE input and the final MSQPE product with respect to MAE and CC (Figs. 13a,d), yet MSQPE had more events ranked in the top two for the MBR and ME 
a)

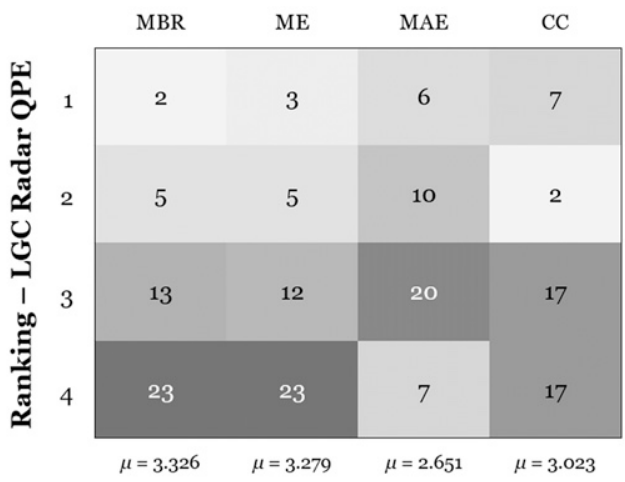

c)

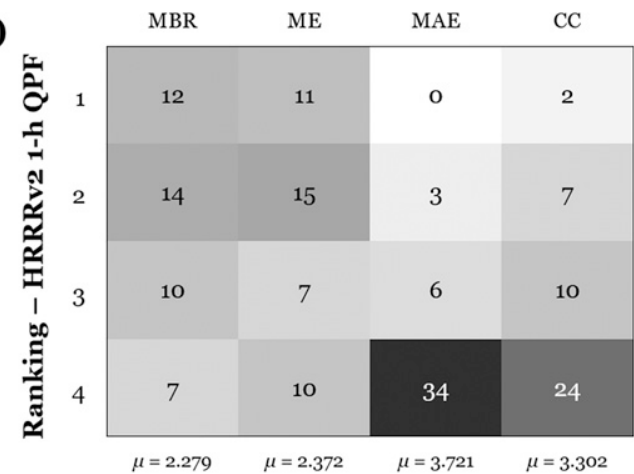

b)

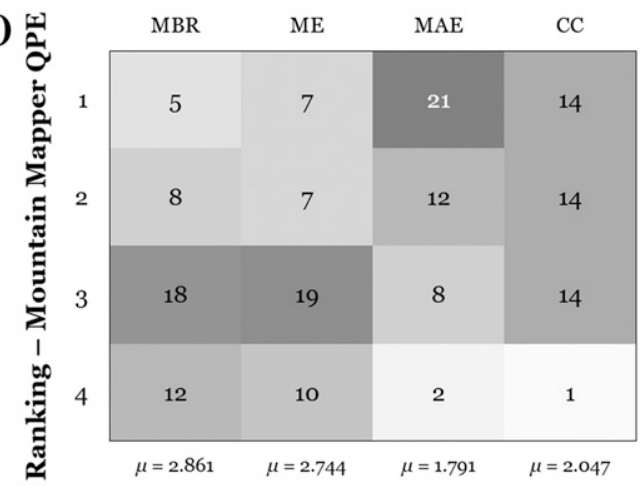

d)

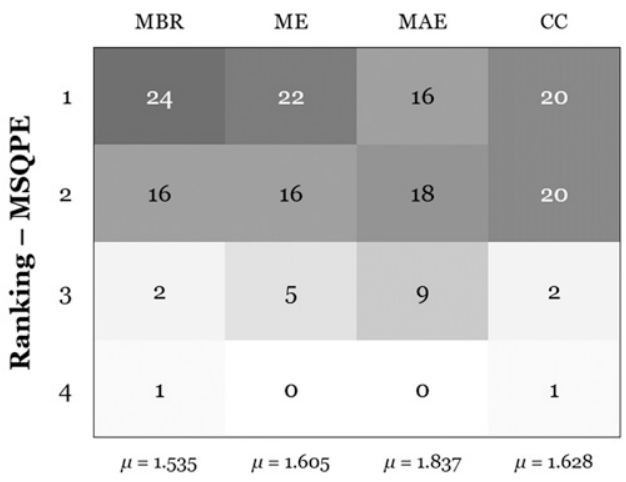

FIG. 11. Cumulative rankings of all individual daily events evaluated by each statistical measure for (a) MRMS LGC radar QPE, (b) MRMS Mountain Mapper QPE, (c) HRRRv2 1-h QPF, and (d) MSQPE. Darker shadings correlate to the more times a precipitation product was ranked at that level compared to the other precipitation products.

values (22) than LGC radar QPE (13). The Mountain Mapper QPE consistently displayed the greatest bias among the four products through its systematic underestimation of precipitation, and it was generally ranked third for MAE and CC values (Fig. 13b). The HRRRv2 1-h QPF MBR and CC rankings were scattered among the 25 eastern CONUS events, but it constantly had the greatest MAE and lowest CC values (Fig. 13c). The MSQPE product across the four statistical categories was ranked first at a rate of $42 \%$ followed by LGC radar QPE at 35\% (Table 5), yet the combination of the LGC radar QPE with the gap-filling inputs allowed MSQPE to be ranked first or second $94 \%$ of the time. The differences between MSQPE and the best ranked input for instances when MSQPE was not ranked first were minimal. All MSQPE MAE values that were not ranked first were $<0.3 \mathrm{~mm}$ of the best ranked input, and all CC values were within 0.007 of the best ranked input.

\section{b. Precipitation coverage analysis}

The perspective from $G, R$ comparisons demonstrated an improvement in coverage while minimizing the addition of false precipitation areas for the western CONUS events. The average percent of $G, R>0$ pairings increased from $70.694 \%$ using LGC radar QPE to $78.267 \%$ with MSQPE (Table 6); moreover, MSQPE had better median, average, and standard deviation values compared to its input sources. Box-and-whisker depictions of the $G, R>0$ comparisons further

TABLE 3. The percent of the 43 evaluated cases over the western CONUS domain that were ranked first, first or second, and first through third for the three input precipitation products and the MSQPE product. The best value in each statistical category is italicized.

\begin{tabular}{lcccc}
\hline \hline & LGC radar QPE & Mountain Mapper QPE & HRRRv2 1-h QPF & MSQPE \\
\hline Rank percentage: 1 & 10.47 & 27.33 & 14.53 & 47.67 \\
Rank percentage: $1-2$ & 23.26 & 51.16 & 37.21 & 88.37 \\
Rank percentage: $1-3$ & 59.30 & 85.74 & 56.40 & 98.84 \\
\hline
\end{tabular}


TABLE 4. As in Table 2, but for the 25 eastern CONUS events.

\begin{tabular}{|c|c|c|c|c|c|}
\hline & & LGC radar QPE & Mountain Mapper QPE & HRRRv2 1-h QPF & MSQPE \\
\hline \multirow[t]{3}{*}{ MBR } & Median & 0.919 & 0.862 & 1.030 & 0.952 \\
\hline & $\mu$ & 0.922 & 0.839 & 1.090 & 0.955 \\
\hline & $\sigma$ & 0.061 & 0.098 & 0.243 & 0.077 \\
\hline \multirow[t]{3}{*}{ ME } & Median (mm) & -0.643 & -1.135 & 0.334 & -0.455 \\
\hline & $\mu(\mathrm{mm})$ & -0.708 & -1.208 & 0.222 & -0.475 \\
\hline & $\sigma(\mathrm{mm})$ & 0.559 & 0.605 & 1.158 & 0.581 \\
\hline \multirow[t]{3}{*}{ MAE } & Median (mm) & 2.521 & 2.665 & 4.186 & 2.416 \\
\hline & $\mu(\mathrm{mm})$ & 2.456 & 2.756 & 4.070 & 2.477 \\
\hline & $\sigma(\mathrm{mm})$ & 0.635 & 0.732 & 1.202 & 0.632 \\
\hline \multirow[t]{3}{*}{$\mathrm{CC}$} & Median & 0.926 & 0.887 & 0.779 & 0.929 \\
\hline & $\mu$ & 0.907 & 0.879 & 0.771 & 0.915 \\
\hline & $\sigma$ & 0.053 & 0.055 & 0.092 & 0.038 \\
\hline
\end{tabular}

demonstrate the improvement of MSQPE over the input precipitation sources (Fig. 14a). The HRRRv2 1-h QPF had similar interquartile ranges and standard deviations, yet the median and average values were about 2\%-3\% lower than MSQPE. Mountain Mapper QPE also achieved similar statistical performances yet struggled in some events due to lack of gauge coverage in certain regions to interpolate nonzero observations or impacts from winter precipitation preventing the measurement of liquid equivalent values.

More significant improvements were noted in the $G>0$, $R=0$ analysis. The percent of instances LGC radar QPE missed precipitation decreased to $13.565 \%$ of pairings classified as $G>0, R=0$ for MSQPE (Table 6). The 75th percentile of the $G>0, R=0$ pairings was reduced from $30.85 \%$ for LGC radar QPE to $17.66 \%$ when applying the MSQPE scheme (Fig. 14b).
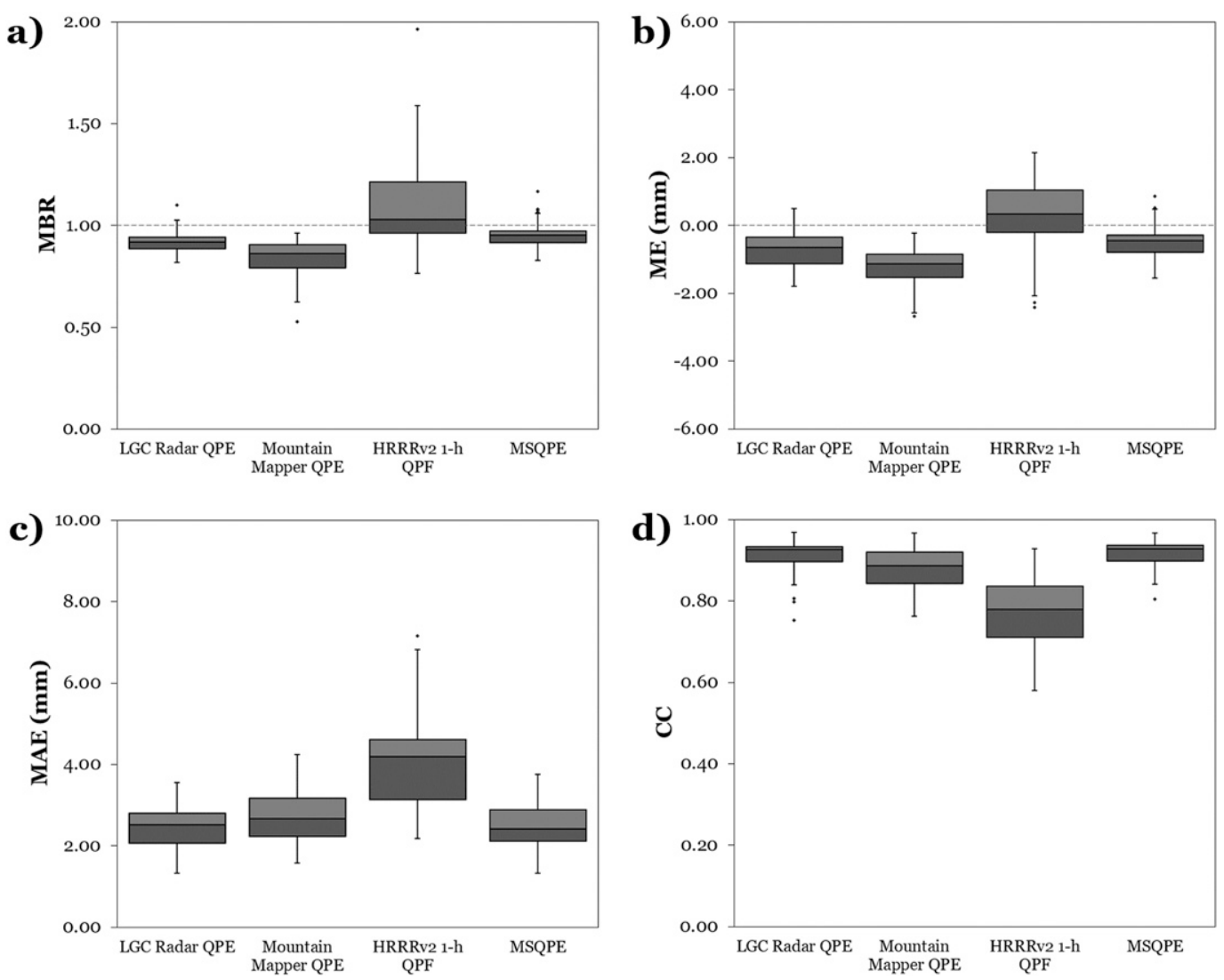

FIG. 12. As in Fig. 10, but for the 25 eastern CONUS events. 
a)

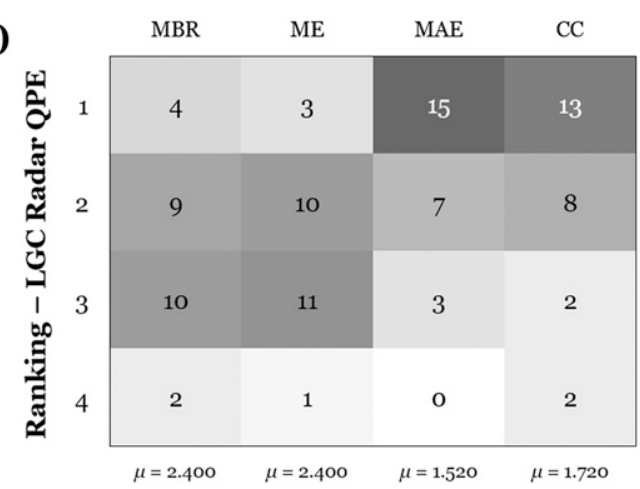

c)

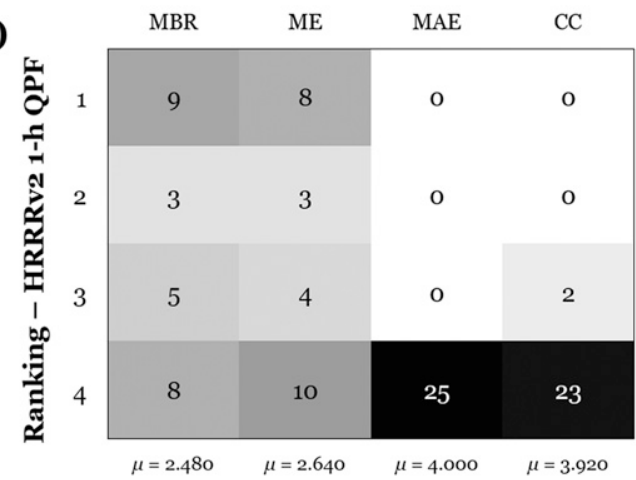

b)

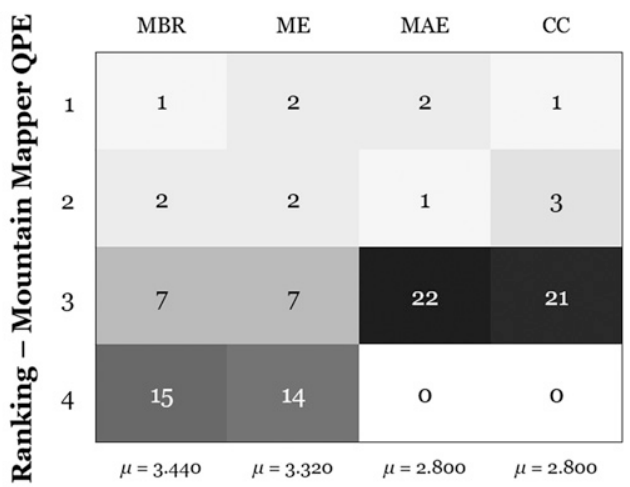

d)

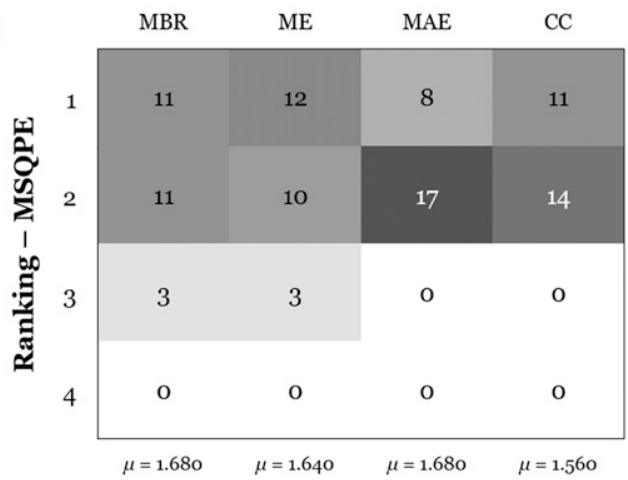

FIG. 13. As in Fig. 11, but for the 25 eastern CONUS events.

The MSQPE, Mountain Mapper QPE, and HRRRv2 precipitation products all had similar statistical performances with reduced instances of missed precipitation compared to LGC radar QPE. Only a small proportion of cases had the percent of $G>0, R=0$ pairings below $5 \%$. It is assumed that inaccurate nonzero observations, nondetectable near-surface hydrometeors (e.g., fog or mist), condensation, or winter precipitation impacts (e.g., blowing snow or postevent thaw) would prevent near-zero percentages of $G>0$, $R=0$ pairings over large domains.

The LGC radar QPE performed the best overall with minimizing false precipitation coverage with an average of $7.295 \%$ of $G, R$ comparisons classified as $G=0, R>0$. This can be contributed to the greater percentages of missed precipitation due to insufficient radar coverage and the utilization of an evaporation correction scheme in MRMS to reduce false light precipitation (Martinaitis et al. 2018). The increase of false precipitation in MSQPE was minimal over LGC radar QPE (Table 6; Fig. 14c). This is attributed to the blending of the other precipitation sources into the MSQPE scheme that also had higher percentages of $G=0, R>0$ comparisons. The application of reducing blended precipitation values $<0.2 \mathrm{~mm}$ to zero also improved the MSQPE performance over the nonradar inputs.

The eastern CONUS events showed that the statistical measures among the evaluated precipitation products had similar trends to that of the western CONUS analysis with a few notable exceptions (Table 7; Fig. 15). The $G, R>0$ comparisons for LGC Radar QPE were more comparable to Mountain Mapper QPE and HRRRv2 1-h QPF due to greater radar coverage over the eastern CONUS. The increased radar coverage also limited the average percent of $G>0, R=0$ comparisons over

TABLE 5. As in Table 3, but for the 25 eastern CONUS events.

\begin{tabular}{lccrr}
\hline \hline & LGC radar QPE & Mountain Mapper QPE & HRRRv2 1-h QPF & MSQPE \\
\hline Rank percentage: 1 & 35.00 & 6.00 & 17.00 & 42.00 \\
Rank percentage: $1-2$ & 69.00 & 14.00 & 23.00 & 94.00 \\
Rank percentage: $1-3$ & 95.00 & 71.00 & 34.00 & 100.00 \\
\hline
\end{tabular}


TABLE 6. The median, average $(\mu)$, and standard deviation $(\sigma)$ of the three input precipitation products and the MSQPE product across the 43 evaluated cases over the western CONUS domain for the percent of $G, R$ comparisons that are categorized into the following pairings: (a) $G, R>0$, (b) $G>0, R=0$, and (c) $G=0, R>0$. The best value in each statistical category is italicized.

\begin{tabular}{|c|c|c|c|c|c|}
\hline & & LGC radar QPE & Mountain Mapper QPE & HRRRv2 1-h QPF & MSQPE \\
\hline \multirow[t]{3}{*}{$G, R>0$} & Median & 73.845 & 79.240 & 78.380 & 80.204 \\
\hline & $\mu$ & 70.694 & 77.189 & 75.467 & 78.267 \\
\hline & $\sigma$ & 12.250 & 11.697 & 11.173 & 10.217 \\
\hline \multirow[t]{3}{*}{$G>0 ; R=0$} & Median & 20.072 & 10.148 & 12.255 & 11.516 \\
\hline & $\mu$ & 22.011 & 12.945 & 14.606 & 13.565 \\
\hline & $\sigma$ & 10.833 & 9.955 & 8.875 & 7.907 \\
\hline \multirow[t]{3}{*}{$G=0 ; R>0$} & Median & 6.649 & 9.413 & 10.040 & 8.035 \\
\hline & $\mu$ & 7.295 & 9.866 & 9.927 & 8.167 \\
\hline & $\sigma$ & 3.770 & 5.132 & 4.631 & 4.116 \\
\hline
\end{tabular}

the eastern CONUS (11.216\%) versus the western CONUS $(22.011 \%)$. The greater radar coverage area can also explain the domain-wide performance similarities between the LGC radar QPE and the resulting MSQPE product through the $G, R$ comparisons. One notable trend over the eastern CONUS was opposite of that over the western CONUS: the percent of $G=0$, $R>0$ observations decreased from the LGC radar QPE input. This is likely attributed to the nonevaporated precipitation detected by radar at farther distances being correctly removed through the blending of HRRRv2 when it generates zero values over those regions.

\section{Case studies}

a. $17-18$ February 2018

Multiple radar coverage gaps highlighted the challenges of detecting shallow precipitation features and accurately portraying the true areal precipitation extent for this event. Prominent radar coverage gaps can be
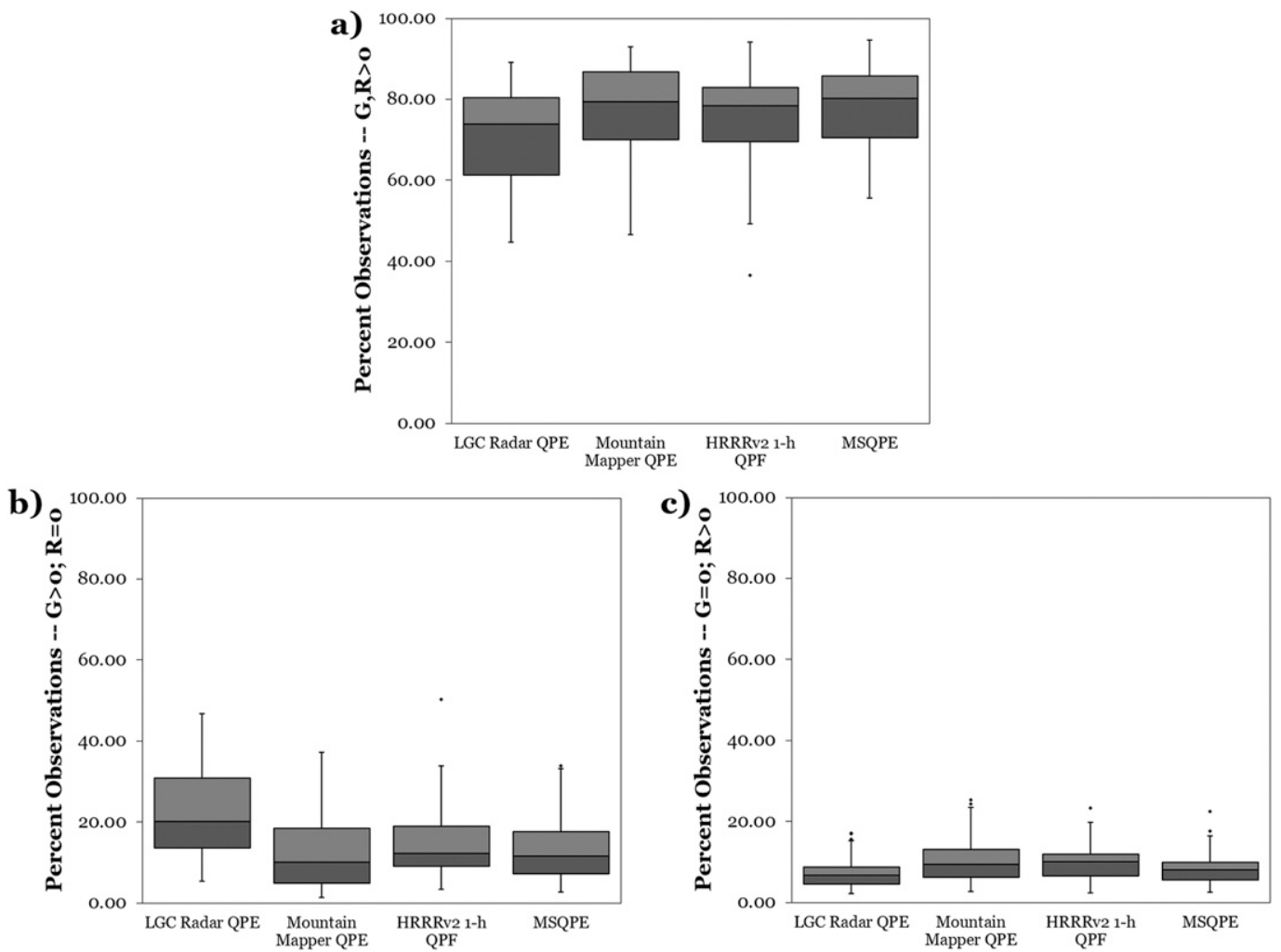

FIG. 14. As in Fig. 10, but for the percent of $G, R$ comparisons that are categorized into the following pairings: (a) $G, R>0$, (b) $G>0, R=0$, and (c) $G=0, R>0$. 
TABLE 7. As in Table 6, but for the 25 eastern CONUS events.

\begin{tabular}{|c|c|c|c|c|c|}
\hline & & LGC radar QPE & Mountain Mapper QPE & HRRRv2 1-h QPF & MSQPE \\
\hline \multirow[t]{3}{*}{$G, R>0$} & Median & 79.534 & 78.552 & 78.280 & 79.831 \\
\hline & $\mu$ & 78.212 & 76.812 & 76.791 & 78.653 \\
\hline & $\sigma$ & 9.987 & 11.965 & 10.193 & 9.799 \\
\hline \multirow[t]{3}{*}{$G>0 ; R=0$} & Median & 7.869 & 8.771 & 7.488 & 8.683 \\
\hline & $\mu$ & 11.216 & 12.468 & 7.643 & 12.518 \\
\hline & $\sigma$ & 7.794 & 10.508 & 4.793 & 8.045 \\
\hline \multirow{3}{*}{$G=0 ; R>0$} & Median & 11.148 & 9.840 & 13.886 & 9.199 \\
\hline & $\mu$ & 10.572 & 10.719 & 15.566 & 8.830 \\
\hline & $\sigma$ & 4.797 & 5.822 & 9.188 & 3.914 \\
\hline
\end{tabular}

seen over Montana, Idaho, northwest Wyoming, northern Washington, and along the Oregon coast (Fig. 16a). The Mountain Mapper QPE (Fig. 16b) and HRRRv2 1-h QPF (Fig. 16c) provided a better depiction of precipitation coverage but with differences in magnitude across the various mountain ranges and eastern Montana. The MSQPE product generated a more continuous precipitation field with more enhanced accumulations across the mountainous terrain while incorporating the HRRRv2 QPF values across the northern Plains. (Fig. 16d). The MBR, ME, and CC values for MSQPE outperformed the three input sources (Table 8). Mountain Mapper QPE exhibited a lower MAE although having a significant underestimation bias; however, the MSQPE MAE was only $0.045 \mathrm{~mm}$ greater but with a near-ideal MBR of 0.965 . The $G, R$ comparisons between Mountain Mapper QPE, HRRRv2 QPF, and MSQPE had similar distributions; moreover, the differences in the $G, R>0$ and $G>0, R=0$ categories between MSQPE and the LGC radar QPE demonstrate how the merged precipitation approach provides a more representative depiction of precipitation coverage based on the gauge observations.

Focused analyses of the LGC radar QPE and MSQPE products over the eastern Washington to western Montana region emphasized the impacts of gap-filling prominent
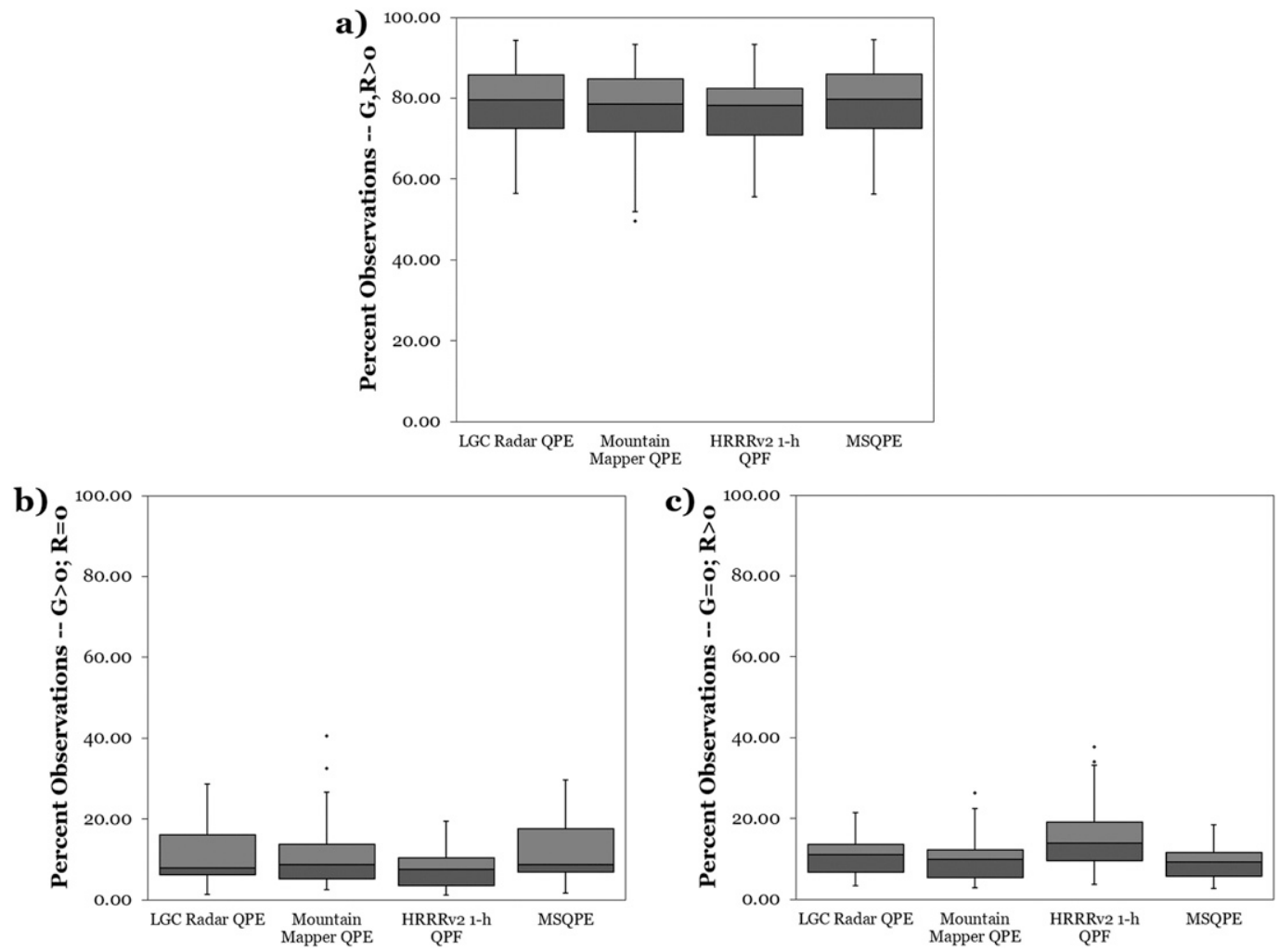

FIG. 15. As in Fig. 14, but for the 25 eastern CONUS events. 

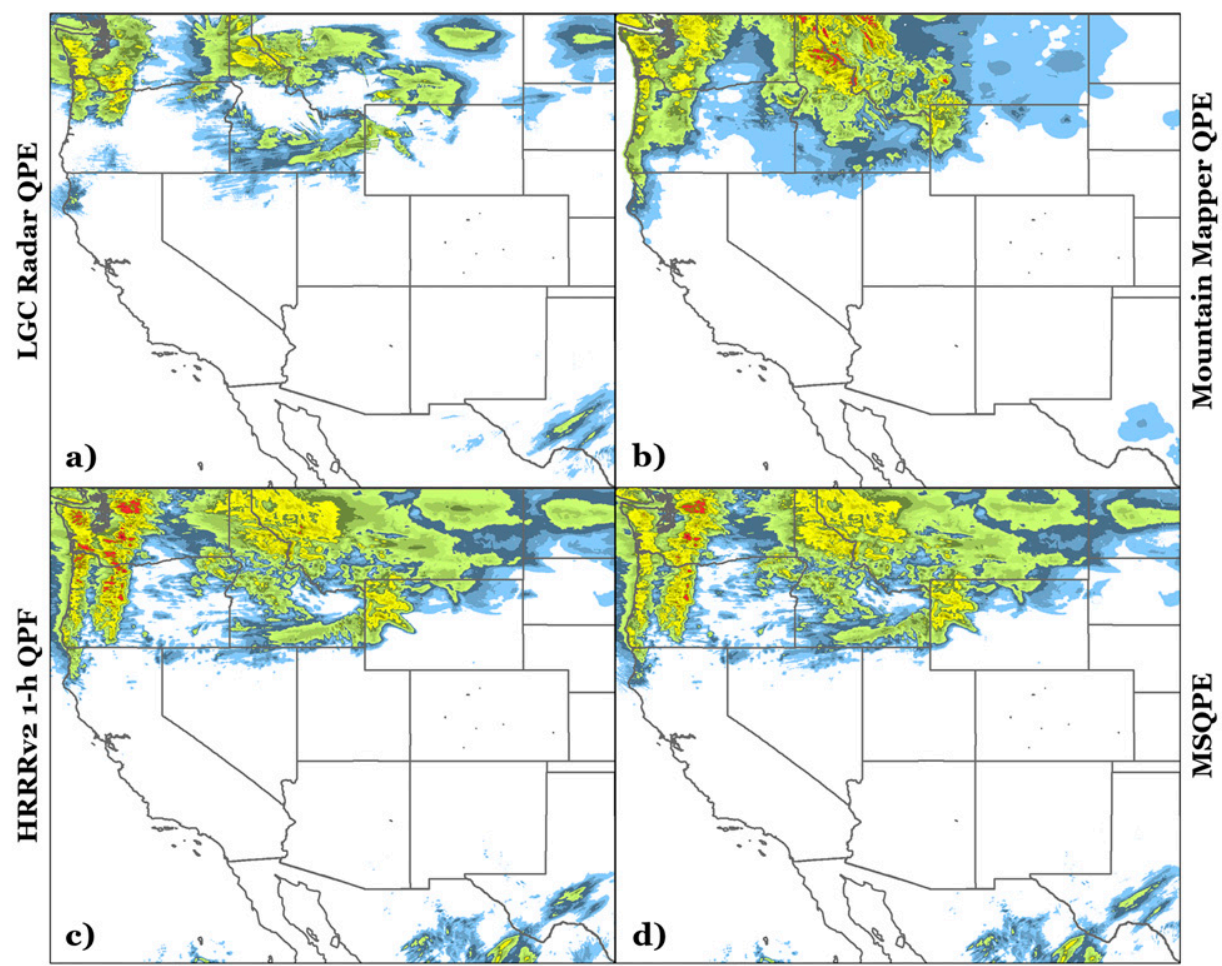

b)
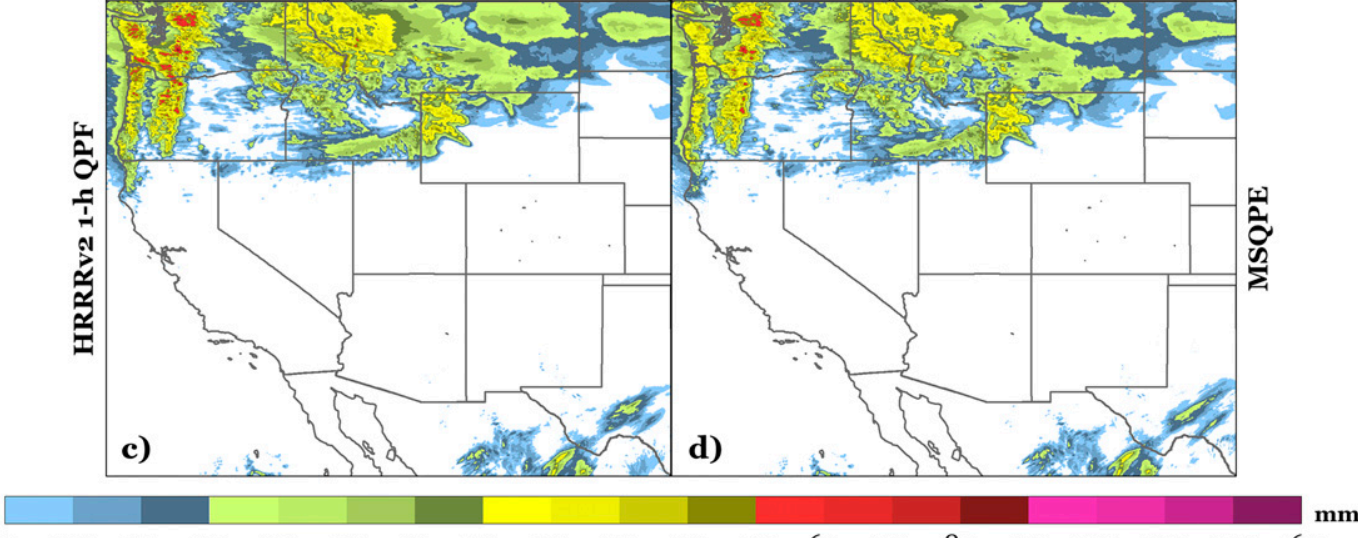

\begin{tabular}{llllllllllllllllllll}
\hline & 1.0 & 2.5 & 5.0 & 7.5 & 10 & 15 & 20 & 25 & 30 & 40 & 50 & 60 & 70 & 80 & 90 & 100 & 120 & 140 & 160
\end{tabular}

FIG. 16. 24-h precipitation accumulation of (a) MRMS LGC radar QPE, (b) MRMS Mountain Mapper QPE, (c) HRRRv2 1-h QPF, and (d) MSQPE QPE over the full western CONUS study domain for the period ending 1400 UTC 18 Feb 2018.

radar coverage gaps that initially resulted in zero accumulated precipitation by LGC radar QPE (Figs. 17a,b); moreover, nonzero accumulation discontinuities from beam blockages were also mitigated via the MSQPE scheme. The various radar coverage challenges resulted in $19.75 \%$ of $G>0, R=0$ pairings for LGC radar QPE and generated a poorly correlated underestimation MBR with significant error values (Table 9). This was also reflected in the scatterplot of CoCoRaHS observations versus LGC radar QPE, notably with the $G, R$ comparisons located along the $x$ axis (Fig. 17c).
Application of the MSQPE scheme resulted in a slight overestimation bias for this area while reducing the $\mathrm{ME}$ and MAE by $84.0 \%$ and $32.1 \%$, respectively. The CC value was improved by 0.196 to 0.774 , and the percent of $G>0, R=0$ pairings was significantly reduced (Table 9; Fig. 17d).

The native hourly accumulations of LGC radar QPE and MSQPE demonstrated how radar coverage issues were resolved throughout this event, especially in northern Idaho and far western Montana (Fig. 18). Percent contribution plots characterized the extent of

TABLE 8. Statistical measures MBR, ME, MAE, and CC along with the percent of $G, R$ comparisons categorized into the $G, R>0$, $G>0, R=0$, and $G=0, R>0$ pairings for the three input precipitation products and the final MSQPE product over the full western CONUS study domain for the $17-18$ Feb 2018 event. The best value in each statistical category is italicized.

\begin{tabular}{lccrr}
\hline \hline & LGC radar QPE & Mountain Mapper QPE & HRRRv2 1-h QPF & MSQPE \\
\hline MBR & 0.539 & 0.756 & 1.093 & 0.965 \\
ME $(\mathrm{mm})$ & -3.116 & -1.654 & 0.619 & -0.235 \\
MAE $(\mathrm{mm})$ & 3.963 & 2.682 & 3.176 & 2.727 \\
CC & 0.660 & 0.817 & 0.803 & 0.822 \\
$G, R>0$ & $62.94 \%$ & $79.42 \%$ & $79.77 \%$ & $79.61 \%$ \\
$G>0 ; R=0$ & $33.90 \%$ & $17.81 \%$ & $15.21 \%$ & $16.10 \%$ \\
$G=0 ; R>0$ & $3.16 \%$ & $2.77 \%$ & $5.02 \%$ & $4.29 \%$ \\
\hline
\end{tabular}


LGC Radar QPE
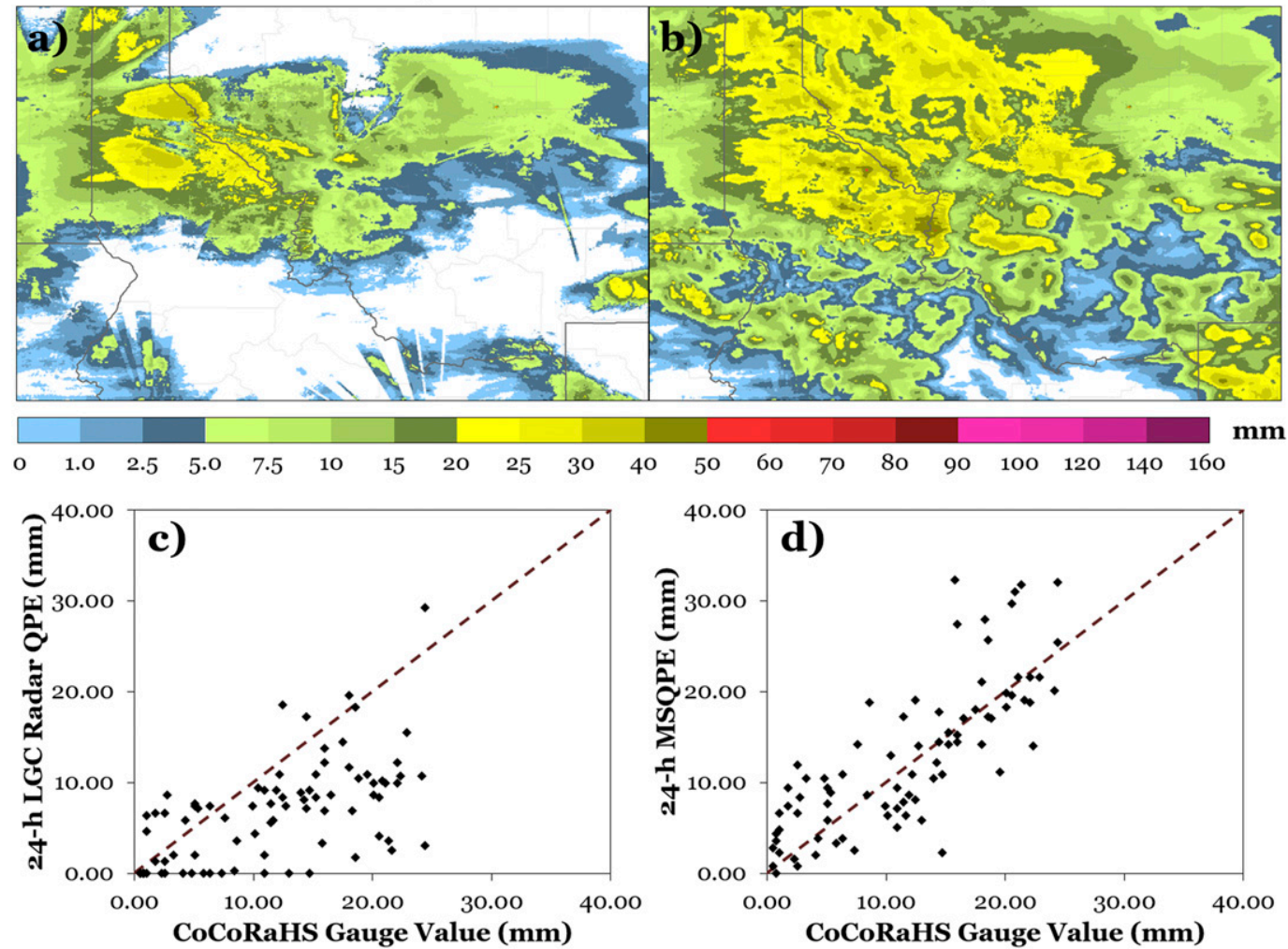

FIG. 17. 24-h precipitation accumulation of (a) MRMS LGC radar QPE and (b) MSQPE QPE across eastern Washington, northern Idaho, and western Montana for the 24-h period ending 1400 UTC 18 Feb 2018. This focused domain is bounded by the northwest corner $49.0^{\circ} \mathrm{N}, 118.0^{\circ} \mathrm{W}$ and the southeast corner $44.0^{\circ} \mathrm{N}, 110.0^{\circ} \mathrm{W}$. Below are the scatterplots of (c) MRMS LGC radar QPE and (d) MSQPE QPE compared to independent CoCoRaHS gauge observations. The dashed line represents the one-to-one line between the CoCoRaHS gauges and the gridded QPE values.

radar coverage utilized by the MSQPE scheme and how the other sources compensated for the coverage (Fig. 19). The retention of radar coverage in MSQPE was minimal due to subfreezing surface temperatures reducing RQI values via Eq. (5). Mountain Mapper QPE was only locally applied during the first half of the event across the windward side of the Rocky Mountains in areas where above-freezing wet-bulb temperatures were modeled by the HRRRv2. This resulted in the HRRRv2 1-h QPFs being the dominant gap-filling source across the focused domain.

\section{b. 12-13 February 2019}

The 12-13 February 2019 event depicted how the MSQPE scheme can be applicable over the eastern CONUS while demonstrating how the overshooting of precipitation features by radars can be compensated for. The radar coverage of the 24-h accumulations ending 1200 UTC 13 February 2019 did not contain prominent gaps resulting in zero accumulated precipitation, yet circular artifacts were prevalent throughout the northern extent of the eastern CONUS domain due to overshooting precipitation (Fig. 20a). Both Mountain Mapper QPE and HRRRv2 1-h QPF had similar accumulation coverages but varying accumulation magnitudes (Figs. 20b,c), and their contributions to MSQPE yielded a more realistic depiction of

TABLE 9. As in Table 8, but for the focused domain bounded by the northwest corner $49.0^{\circ} \mathrm{N}, 118.0^{\circ} \mathrm{W}$ and the southeast corner $44.0^{\circ} \mathrm{N}, 110.0^{\circ} \mathrm{W}$ and only for the comparison of MRMS LGC radar QPE vs MSQPE of the 17-18 Feb 2018 event.

\begin{tabular}{lcc}
\hline & LGC radar QPE & MSQPE \\
\hline MBR & 0.572 & 1.087 \\
ME $(\mathrm{mm})$ & -5.046 & 1.025 \\
$\operatorname{MAE}(\mathrm{mm})$ & 6.231 & 4.030 \\
CC & 0.578 & 0.787 \\
$G, R>0$ & $80.25 \%$ & $98.77 \%$ \\
$G>0 ; R=0$ & $19.75 \%$ & $1.23 \%$ \\
$G=0 ; R>0$ & $0.00 \%$ & $0.00 \%$ \\
\hline
\end{tabular}




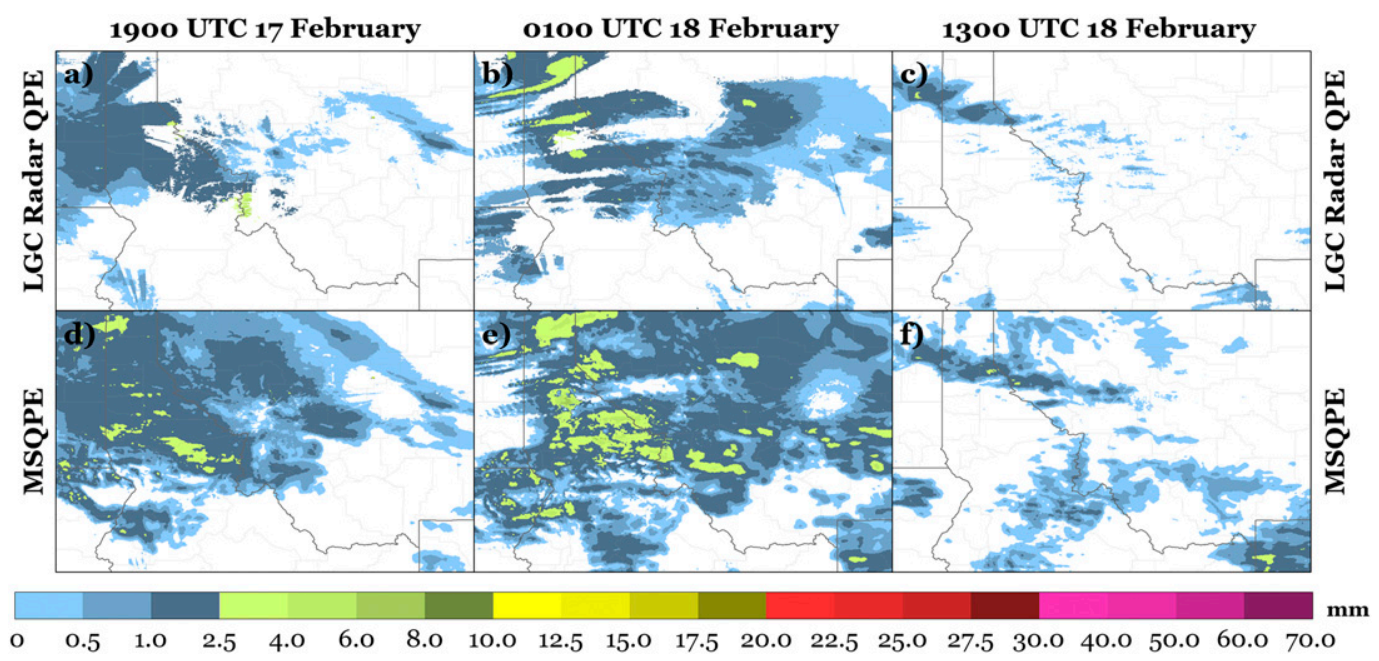

FIG. 18. Hourly precipitation accumulation of (top) LGC radar QPE and (bottom) MSQPE across eastern Washington, northern Idaho, and western Montana ending at the following times: (a),(d) 1900 UTC 17 Feb 2018 , (b),(e) 0100 UTC 18 Feb 2018, and (c),(f) 1300 UTC 18 Feb 2018. This focused domain is bounded by the northwest corner $49.0^{\circ} \mathrm{N}, 118.0^{\circ} \mathrm{W}$ and the southeast corner $44.0^{\circ} \mathrm{N}, 110.0^{\circ} \mathrm{W}$.

precipitation accumulations by mitigating radar coverage challenges (Fig. 20d). Statistical analyses for this event showed MSQPE improved over all three input sources (Table 10), while the $G, R$ comparisons were similar between MSQPE and the three input sources.

Examination of the 24-h accumulations of LGC radar QPE and MSQPE over the New England area validated the reduction of the underestimation bias from the undersampling of hydrometeors (Fig. 21). The area from Vermont to Maine had prominent areas of LGC radar QPE accumulations of $<15 \mathrm{~mm}$ with localized areas of $<5 \mathrm{~mm}$, whereas MSQPE had large areal depictions of $20-40 \mathrm{~mm}$ over the $24-\mathrm{h}$ period ending 1200 UTC 13 February 2019 (Figs. 21a,b). The scatterplots versus CoCoRaHS observations reflected the underestimation of precipitation with LGC radar QPE and the improvement with MSQPE despite some

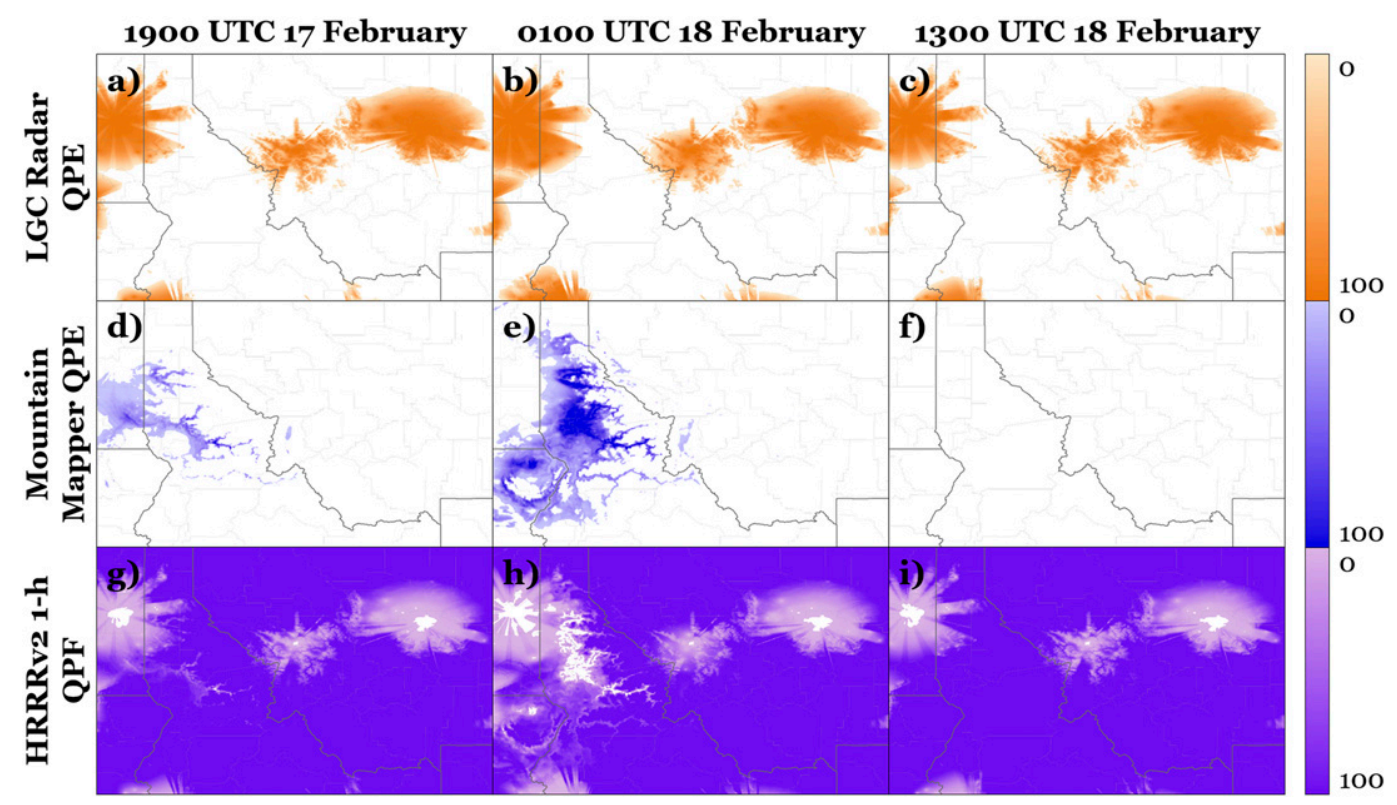

FIG. 19. The percent contribution of (a)-(c) LGC radar QPE, (d)-(f) Mountain Mapper QPE, and (g)-(i) HRRRv2 1-h QPF for the same 1-h time periods denoted in Fig. 18. 


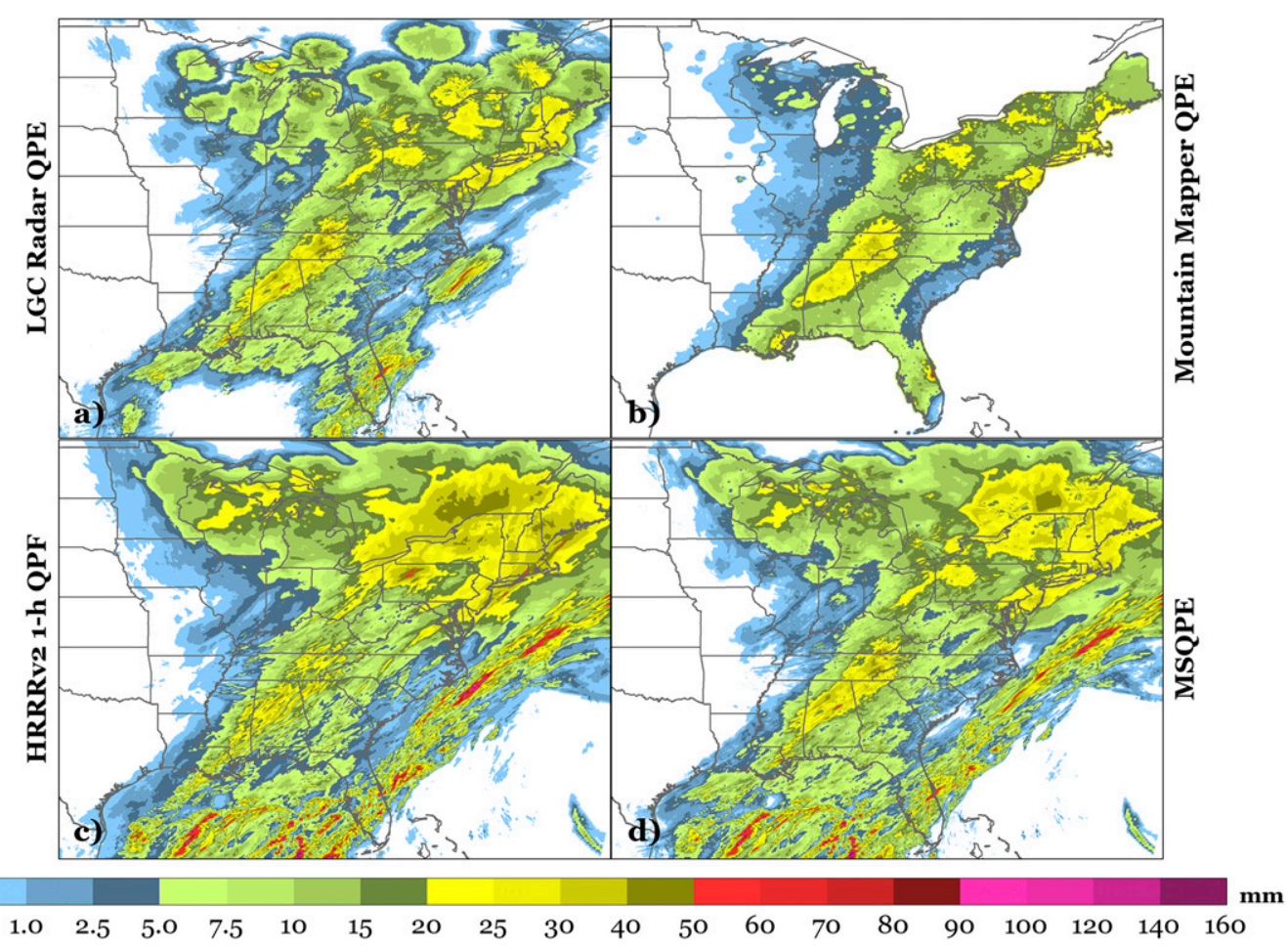

FIG. 20. As in Fig. 16, but for the full eastern CONUS study domain for the period ending 1200 UTC 13 Feb 2019.

notable scatter remaining in the data (Figs. 21c,d). The focused domain MBR was improved from 0.771 to 0.922 with the ME and MAE being reduced by $66 \%$ and $26 \%$, respectively (Table 11 ). The scatter in data for both products yielded low overall CC values, but the MSQPE product improved the CC by $7.0 \%$. The $G, R$ comparisons were identical between LGC radar QPE and MSQPE.

Analyses of the event at the native hourly scale demonstrated how coverage areas were filled while the overshooting of precipitation was mitigated through the MSQPE logic (Fig. 22). Increased precipitation coverage was most prevalent early in the event while improved precipitation magnitudes were characterized across the duration of the event. The surface and atmospheric environment variables greatly influenced the percent contribution of the three input sources (Fig. 23). The LGC radar QPE contribution varied across the focused domain with more expansive utilization of radar-derived QPE to the south due to higher freezing-level heights associated with an occluded front. The HRRRv2 QPF was the sole source of filling radar coverage gaps for this event. The Mountain Mapper QPE did not contribute to MSQPE due to subfreezing wet-bulb temperatures in the mountainous terrain north of the occluded front and the expanded radar coverage south of the front.

\section{Summary}

The primary objective of the MSQPE product is to provide a methodology and a resulting high

TABLE 10. As in Table 8, but over the full eastern CONUS study domain for the 12-13 Feb 2019 event.

\begin{tabular}{|c|c|c|c|c|}
\hline & LGC radar QPE & Mountain Mapper QPE & HRRRv2 1-h QPF & MSQPE \\
\hline MBR & 0.927 & 0.871 & 1.093 & 0.972 \\
\hline $\operatorname{ME}(\mathrm{mm})$ & -0.831 & -1.458 & 1.050 & -0.316 \\
\hline $\operatorname{MAE}(\mathrm{mm})$ & 3.216 & 3.527 & 4.961 & 2.981 \\
\hline $\mathrm{CC}$ & 0.875 & 0.843 & 0.773 & 0.897 \\
\hline$G, R>0$ & $91.81 \%$ & $91.23 \%$ & $92.41 \%$ & $91.94 \%$ \\
\hline$G>0 ; R=0$ & $3.12 \%$ & $4.29 \%$ & $1.83 \%$ & $3.38 \%$ \\
\hline$G=0 ; R>0$ & $5.07 \%$ & $4.48 \%$ & $5.76 \%$ & $4.68 \%$ \\
\hline
\end{tabular}



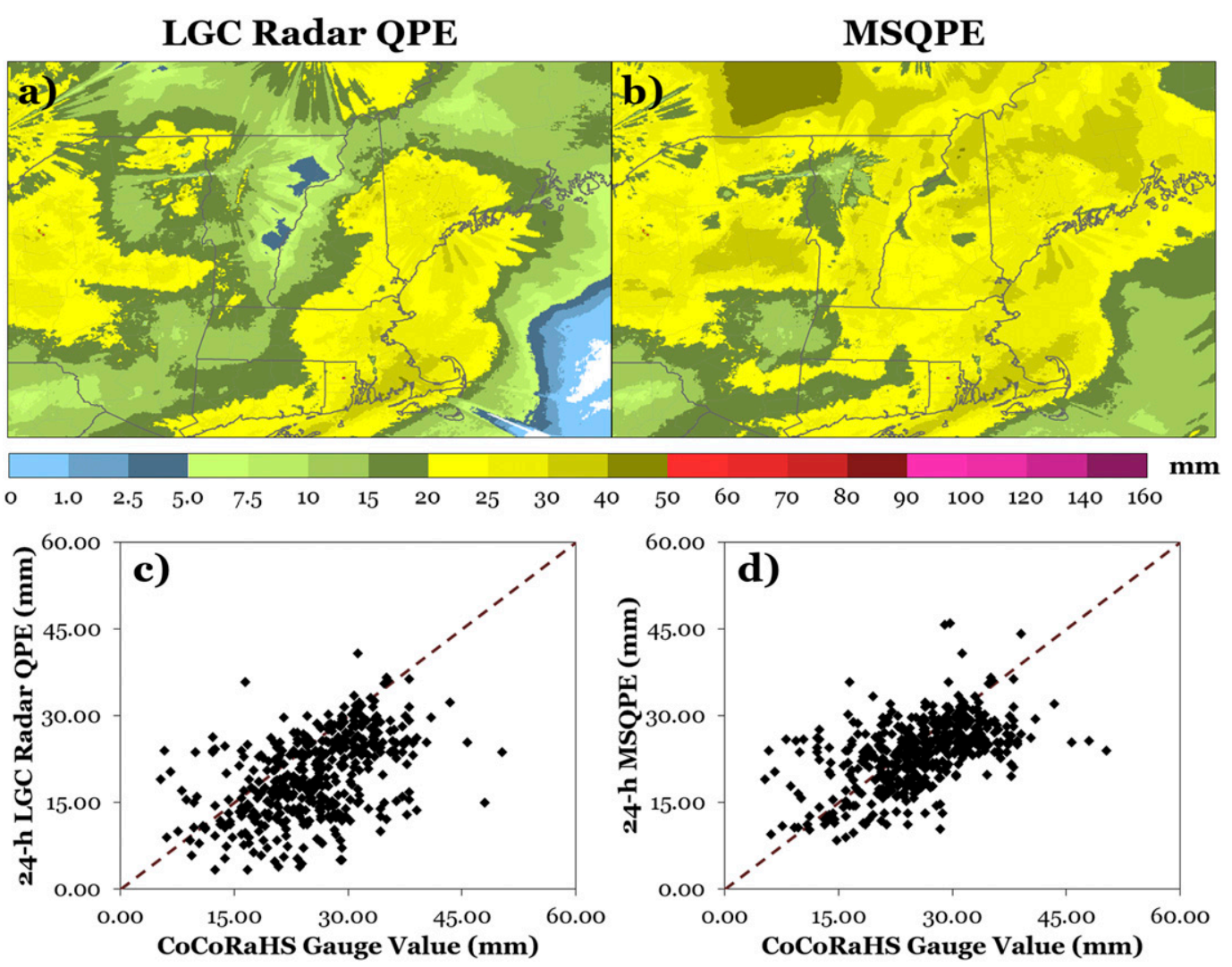

FIG. 21. As in Fig. 17, but for the New England area bounded by the northwest corner $46.0^{\circ} \mathrm{N}, 76.0^{\circ} \mathrm{W}$ and the southeast corner $41.0^{\circ} \mathrm{N}, 68.0^{\circ} \mathrm{W}$ for the 24 -h period ending 1200 UTC 13 Feb 2019.

spatiotemporal resolution QPE to improve spatial representations of precipitation. Radar-derived QPE is utilized as the primary precipitation source in regions where radar coverage is deemed as adequate. Gauge observations, precipitation climatologies, and NWP short-term QPFs are seamlessly blended with the radar-based QPEs to mitigate the challenges of overshooting precipitation, significant beam blockages, and poor radar network densities. The MRMS Mountain Mapper QPE is utilized in stratiform rain only in regions of complex terrain, while HRRRv2 1-h QPFs are incorporated everywhere else as radar gap-filling solutions. An updated MRMS RQI product influences the coverage of adequate radar data. Surface and atmospheric conditions, topography, gauge locations, and precipitation values determined how each precipitation source is weighted within the MSQPE scheme.

MSQPE consistently improved upon the radar-based QPE in terms of statistical measures and the proportion of $G, R$ comparisons depicting accurate precipitation coverages. The MSQPE technique generally had improved evaluation results over all the input precipitation sources, and when the MSQPE was not statistically the best product, the differences between it and the best ranked input precipitation product was mostly negligible. The two detailed case evaluations presented demonstrated how the MSQPE scheme can adequately fill radar coverage gaps where precipitation was not detected due to significant beam blockage or poor coverage; moreover, underestimation biases from radar overshooting precipitation features were also mitigated.

The skill of the MSQPE scheme was only as good as the quality and availability of its input sources. The LGC radar QPE was generally the superior input precipitation

TABLE 11. As in Table 9, but for the focused domain bounded by the northwest corner $46.0^{\circ} \mathrm{N}, 76.0^{\circ} \mathrm{W}$ and the southeast corner $41.0^{\circ} \mathrm{N}, 68.0^{\circ} \mathrm{W}$ of the $12-13 \mathrm{Feb} 2019$ event.

\begin{tabular}{lcc}
\hline \hline & LGC radar QPE & MSQPE \\
\hline MBR & 0.771 & 0.922 \\
ME $(\mathrm{mm})$ & -5.855 & -1.987 \\
MAE $(\mathrm{mm})$ & 7.361 & 5.412 \\
CC & 0.471 & 0.504 \\
$G, R>0$ & $100.00 \%$ & $100.00 \%$ \\
$G>0 ; R=0$ & $0.00 \%$ & $0.00 \%$ \\
$G=0 ; R>0$ & $0.00 \%$ & $0.00 \%$ \\
\hline
\end{tabular}




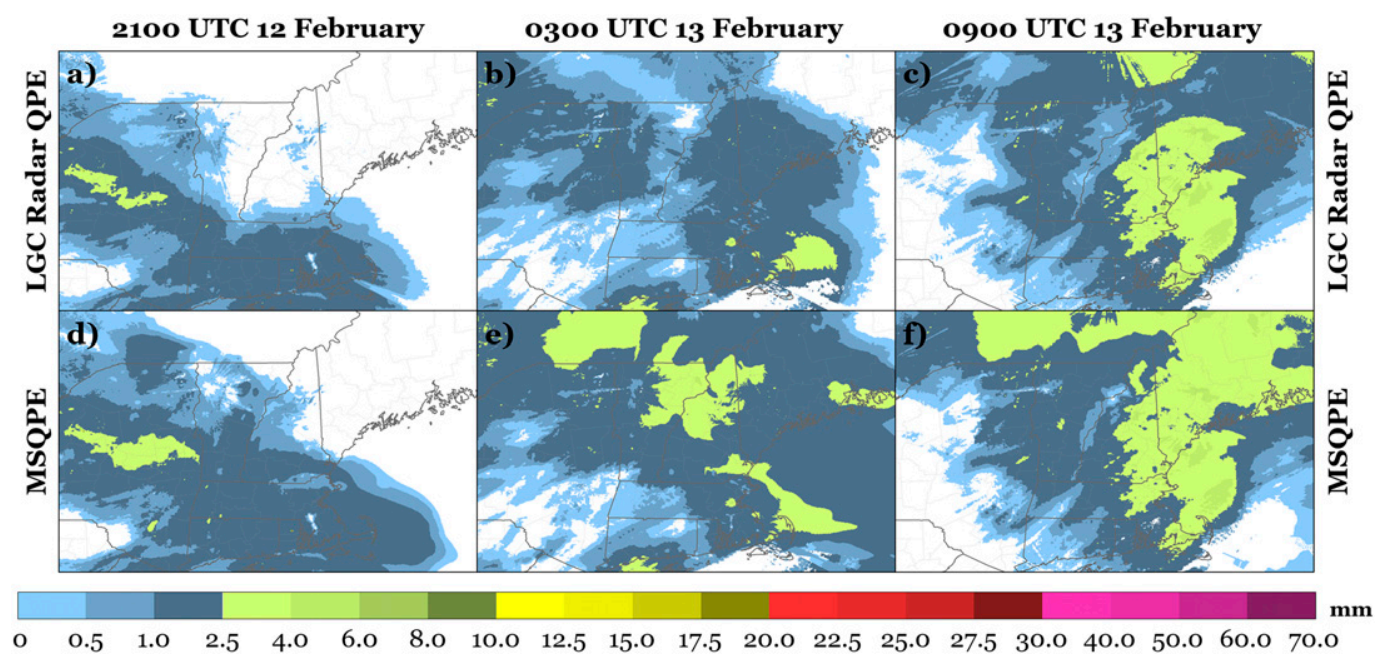

FIG. 22. As in Fig. 18, but for the New England area ending at the following times: (a),(d) 2100 UTC 12 Feb 2019, (b),(e) 0300 UTC 13 Feb 2019, and (c),(f) 0900 UTC 13 Feb 2019. This focused domain is bounded by the northwest corner $46.0^{\circ} \mathrm{N}, 76.0^{\circ} \mathrm{W}$ and the southeast corner $41.0^{\circ} \mathrm{N}, 68.0^{\circ} \mathrm{W}$.

source where adequate radar and gauge observations were present. Improved observational densities and data quality would inherently advance the quality of QPE, which is demonstrated by the skill of the LGC radar QPE between the western CONUS domain and the more data rich eastern CONUS domain. The HRRRv2 1-h QPFs were shown to have adequate skill in portraying observed precipitation to successfully assist in filling radar coverage gaps. Some overall statistical measures of model-derived QPF appear to have exceeded that of MRMS LGC radar QPE and Mountain
Mapper QPE; however, larger standard deviations in these statistical measures were also present based on large variations of QPF biases. Operational advancements to the HRRR model would improve the gapfilling precipitation in areas where HRRR QPFs would be the primary gap-filling source. A gauge-based bias correction of NWP QPFs is under consideration to improve MSQPE skill in the gap-filling regions.

The satellite-derived QPE (i.e., SCaMPR) considered for this study had significant challenges in spatially detecting precipitation and providing accurate

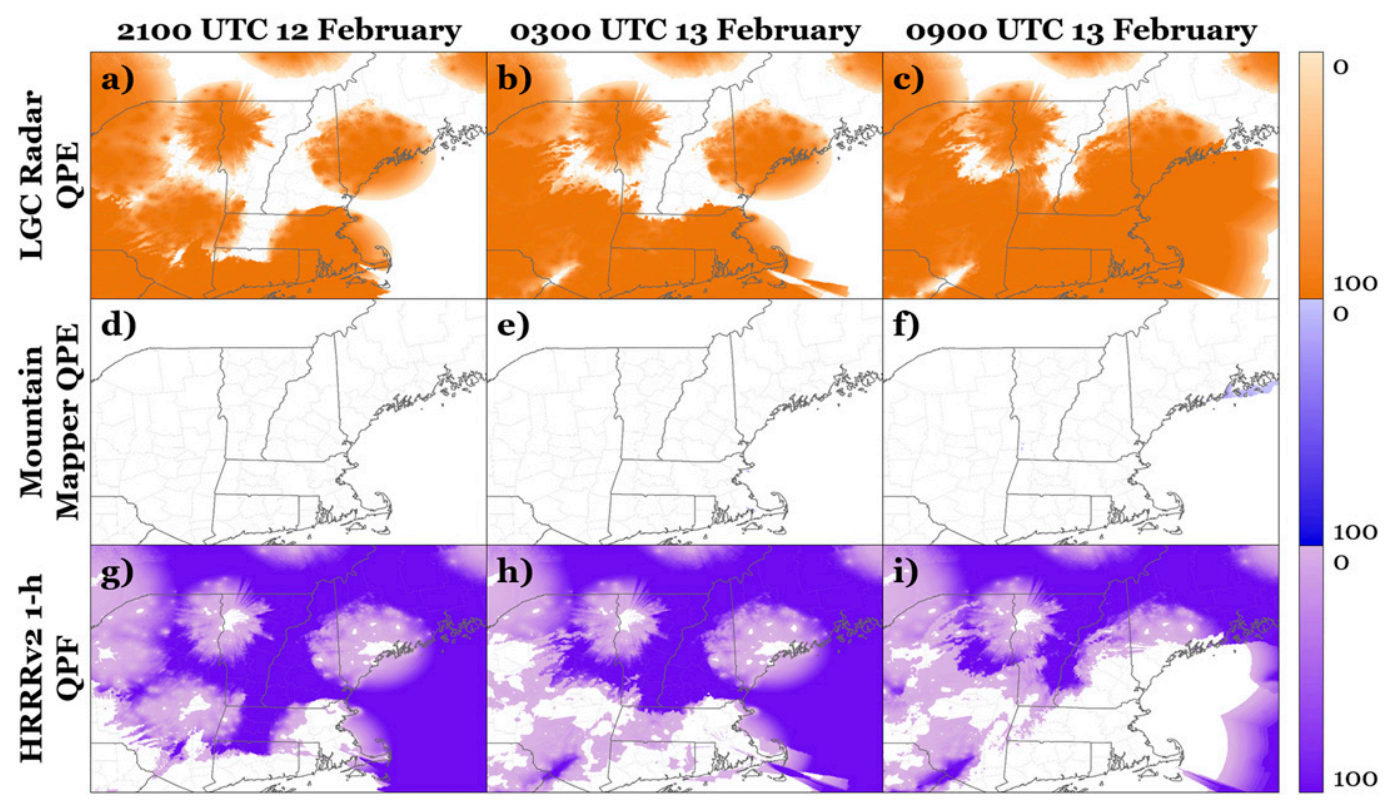

FIG. 23. As in Fig. 19, but for the same 1-h time periods denoted in Fig. 22. 
precipitation magnitudes. Other satellite-derived QPEs have improved precipitation detection and accuracy; however, they generally lack the short-term data latency required for real-time use or an appropriate spatial resolution to properly capture precipitation gradients. Flexibility within the MSQPE code allows for a future implementation of the MSQPE algorithm with a satellite-derived QPE component when satellite QPE performance metrics are deemed satisfactory for use. There are current efforts across the research community to improve satellite-derived QPE using the latest GOES satellites.

Continuous evaluations of the products can result in future refinements to the algorithm in order to best meet the needs of operational end-users. Research efforts to develop the MSQPE scheme in future MRMS domains over Alaska, Hawaii, the Caribbean, and Guam are also ongoing. The MSQPE scheme for these non-CONUS regions will begin with the foundational logic presented in this study and later modified to handle the unique precipitation regimes, data coverage challenges, and the availability of various observations and NWP forecasts for each future MRMS domain.

Acknowledgments. The authors thank the anonymous reviewers for their comments and assistance. The authors also thank Pierre-Emmanuel Kirstetter (OU School of Meteorology) for his insight and review of the study. This research was supported by a grant from the NOAA Office of Weather and Air Quality (OWAQ) Joint Technology Transfer Initiative (JTTI) Award NA17OAR4590175. Funding was also provided by NOAA/Office of Oceanic and Atmospheric Research under NOAA-University of Oklahoma Cooperative Agreement NA11OAR4320072, U.S. Department of Commerce.

\section{REFERENCES}

Austin, P. M., 1987: Relation between measured radar reflectivity and surface rainfall. Mon. Wea. Rev., 115, 1053-1070, https:// doi.org/10.1175/1520-0493(1987)115<1053:RBMRRA > 2.0.CO; 2.

Benjamin, S. G., and Coauthors, 2016: A North American hourly assimilation and model forecast cycle: The Rapid Refresh. Mon. Wea. Rev., 144, 1669-1694, https://doi.org/10.1175/ MWR-D-15-0242.1.

Chen, S., and Coauthors, 2013: Evaluation and uncertainty estimation of NOAA/NSSL next-generation National Mosaic Quantitative Precipitation Estimation product (Q2) over the continental United States. J. Hydrometeor., 14, 1308-1322, https://doi.org/10.1175/JHM-D-12-0150.1.

Cifelli, R., N. Doesken, P. Kennedy, L. D. Carey, S. A. Rutledge, C. Gimmestad, and T. Depue, 2005: The Community Collaborative Rain, Hail, and Snow Network: Informal education for scientists and citizens. Bull. Amer. Meteor. Soc., 86, 1069-1078, https://doi.org/10.1175/BAMS-86-8-1069.
Clark, A. J., W. A. Gallus Jr., M. Xue, and F. Kong, 2009: A comparison of precipitation forecast skill between small convection-allowing and large convection parameterizing ensembles. Wea. Forecasting, 24, 1121-1140, https://doi.org/ 10.1175/2009WAF2222222.1.

Daly, C., R. P. Neilson, and D. L. Phillips, 1994: A statisticaltopographic model for mapping climatological precipitation over mountainous terrain. J. Appl. Meteor., 33, 140-158, https://doi.org/10.1175/1520-0450(1994)033<0140:ASTMFM> 2.0.CO;2.

, M. Halbleib, J. Smith, W. Gibson, M. Doggett, G. Taylor, J. Curtis, and P. Pasteris, 2008: Physiographically sensitive mapping of climatological temperature and precipitation across the conterminous United States. Int. J. Climatol., 28, 2031-2064, https://doi.org/10.1002/joc.1688.

Duda, J. D., X. Wang, F. Kong, and M. Xue, 2014: Using varied microphysics to account for uncertainty in warm-season QPF in a convective-allowing ensemble. Mon. Wea. Rev., 142, 2198-2219, https://doi.org/10.1175/MWR-D-13-00297.1.

Germann, U., and J. Joss, 2002: Mesobeta profiles to extrapolate radar precipitation measurements above the Alps to the ground level. J. Appl. Meteor., 41, 542-557, https://doi.org/ 10.1175/1520-0450(2002)041<0542:MPTERP > 2.0.CO;2.

Goodison, B. E., P. Y. T. Louie, and D. Yang, 1998: WMO solid precipitation intercomparison. Instruments and Observing Methods Rep. 67, WMO/TD-872, 212 pp., https:/www.wmo.int/ pages/prog/www/IMOP/publications/IOM-67-solid-precip/ WMOtd872.pdf.

Groisman, P. Ya., and D. R. Legates, 1994: The accuracy of United States precipitation data. Bull. Amer. Meteor. Soc., 75, 215-227, https://doi.org/10.1175/1520-0477(1994)075<0215:TAOUSP> 2.0.CO;2.

Harrison, D. L., S. J. Driscoll, and M. Kitchen, 2000: Improving precipitation estimates from weather radar using quality control and correction techniques. Meteor. Appl., 7, 135144, https://doi.org/10.1017/S1350482700001468.

Helms, D., P. Miller, M. Barth, D. Starosta, B. Gordon, S. Schofield, F. Kelly, and S. Koch, 2009: Status update of the transition from research to operations of the Meteorological Assimilation Data Ingest System. 25th Conf. on Int. Interactive Information and Processing Systems, Phoenix, AZ, Amer. Meteor. Soc., 5A.3, https://ams.confex.com/ams/89annual/ techprogram/paper_149883.htm.

Joss, J., and A. Waldvogel, 1969: Raindrop size distribution and sampling size errors. J. Atmos. Sci., 26, 566-569, https://doi.org/ 10.1175/1520-0469(1969)026<0566:RSDASS > 2.0.CO;2.

Kim, D., B. Nelson, and D. J. Seo, 2009: Characteristics of reprocessed Hydrometeorological Automated Data System (HADS) hourly precipitation data. Wea. Forecasting, 24, 1287-1296, https://doi.org/10.1175/2009WAF2222227.1.

Kitchen, M., R. Brown, and A. G. Davies, 1994: Real-time correction of weather radar data for the effects of bright band, range and orographic growth in widespread precipitation. Quart. J. Roy. Meteor. Soc., 120, 1231-1254, https://doi.org/10.1002/qj.49712051906.

Kondragunta, C., and K. Shrestha, 2006: Automated real-time operational rain gauge quality-control tools in NWS hydrologic operations. 20th Conf. on Hydrology, Boston, MA, Amer. Meteor. Soc., P2.4, https://ams.confex.com/ams/Annual2006/ techprogram/paper_102834.htm.

Kuligowski, R. J., 2002: A self-calibrating real-time GOES rainfall algorithm for short-term rainfall estimates. J. Hydrometeor., 3, 112-130, https://doi.org/10.1175/1525-7541(2002)003<0112:ASCRTG> 2.0.CO;2. 
_ 2010: GOES-R Advanced Baseline Imager (ABI) Algorithm Theoretical Basis Document for Rainfall Rate (QPE). NOAA/NESDIS/STAR Algorithm Theoretical Basis Doc., version 2.0, 44 pp., http://www.goes-r.gov/products/ATBDs/ baseline/Hydro_RRQPE_v2.0_no_color.pdf.

—, Y. Li, Y. Hao, and Y. Zhang, 2016: Improvements to the GOES-R rainfall rate algorithm. J. Hydrometeor., 17, 16931704, https://doi.org/10.1175/JHM-D-15-0186.1.

Larson, L. W., and E. L. Peck, 1974: Accuracy of precipitation measurements for hydrologic modeling. Water Resour. Res., 10, 857-863, https://doi.org/10.1029/WR010i004p00857.

Lawson, J. R., J. S. Kain, N. Yussouf, D. C. Dowell, D. M. Wheatley, K. H. Knopfmeier, and T. A. Jones, 2018: Advancing from convection-allowing NWP to Warn-on-Forecast: Evidence of progress. Wea. Forecasting, 33, 599-607, https://doi.org/10.1175/ WAF-D-17-0145.1.

Lin, C., S. Vasić, A. Kilambi, B. Turner, and I. Zawadzki, 2005: Precipitation forecast skill of numerical weather prediction models and radar nowcasts. Geophys. Res. Lett., 32, L14801, https://doi.org/10.1029/2005GL023451.

Lundquist, J., M. Hughes, E. Gutmann, and S. Kapnick, 2019: Our skill in modeling mountain rain and snow is bypassing the skill of our observational networks. Bull. Amer. Meteor. Soc., 100, 2473-2490, https://doi.org/10.1175/BAMS-D-190001.1.

Maddox, R. A., J. Zhang, J. J. Gourley, and K. W. Howard, 2002: Weather radar coverage over the contiguous United States. Wea. Forecasting, 17, 927-934, https://doi.org/10.1175/15200434(2002)017<0927:WRCOTC>2.0.CO;2.

Mahoney, K. M., and G. M. Lackmann, 2007: The effect of upstream convection on downstream precipitation. Wea. Forecasting, 22, 255-277, https://doi.org/10.1175/WAF986.1.

Martinaitis, S. M., Y. Qi, S. Cocks, L. Tang, B. Kaney, J. Zhang, and K. Howard, 2014: Improving MRMS Q3 precipitation estimation in the western United States: Preliminary results. 39th Natl. Weather Association Annual Meeting, Salt Lake City, UT, National Weather Association, D3.4, https://pdfs.semanticscholar.org/75a4/ e9c8f4e97aeeffc977b09751342eb8b36626.pdf.

_- S. B. Cocks, Y. Qi, B. Kaney, J. Zhang, and K. Howard, 2015: Understanding winter precipitation impacts on automated gauge observations within a real-time system. J. Hydrometeor., 16, 2345-2363, https://doi.org/10.1175/JHM-D-15-0020.1.

_- H. M. Grams, C. Langston, J. Zhang, and K. Howard, 2018: A real-time evaporation correction scheme for radar-derived mosaicked precipitation estimations. J. Hydrometeor., 19, 87111, https://doi.org/10.1175/JHM-D-17-0093.1.

Matsuo, T., and Y. Sasyo, 1981: Non-melting phenomena of snowflakes observed in subsaturated air below freezing level. J. Meteor. Soc. Japan, 59, 26-32, https://doi.org/10.2151/ jmsj1965.59.1_26.

Metcalfe, J. R., and B. E. Goodison, 1992: Automation of winter precipitation estimates: The Canadian experience. Instruments and observing methods, Rep. 49, WMO/TD-462, 81-85.

Miller, P. A., M. Barth, L. Benjamin, R. Artz, and W. Pendergrass, 2007: MADIS support for UrbaNet. 14th Symp. on Meteorological Observation and Instrumentation/16th Conf. on Applied Climatology, San Antonio, TX, Amer. Meteor. Soc., JP2.5, https://ams.confex.com/ ams/87ANNUAL/webprogram/Paper119116.html.

Pinto, J. O., J. A. Grim, and M. Steiner, 2015: Assessment of the high-resolution rapid refresh model's ability to predict mesoscale convective systems using object-based evaluation. Wea. Forecasting, 30, 892-913, https://doi.org/10.1175/ WAF-D-14-00118.1.
Qi, Y., J. Zhang, and P. Zhang, 2013a: A real-time automated convective and stratiform precipitation segregation algorithm in native radar coordinates. Quart. J. Roy. Meteor. Soc., 139, 2233-2240, https://doi.org/10.1002/qj.2095.

,$--\frac{-}{-}$, and Q. Cao, 2013b: VPR correction of bright band effects in radar QPEs using polarimetric radar observations. J. Geophys. Res. Atmos., 118, 3627-3633, https://doi.org/ 10.1002/JGRD.50364.

—, S. Martinaitis, J. Zhang, and S. Cocks, 2016: A real-time automated quality control of hourly rain gauge data based on multiple sensors in MRMS system. J. Hydrometeor., 17, 16751691, https://doi.org/10.1175/JHM-D-15-0188.1.

Quina, G. S., III, 2003: Statistical and hydrological evaluations of rain gauge- and radar-derived precipitation for the Florida peninsula. M.S. thesis, Dept. of Earth, Ocean and Atmospheric Sciences, Florida State University, $72 \mathrm{pp}$.

Rasmussen, R., and Coauthors, 2012: How well are we measuring snow: The NOAA/FAA/NCAR winter precipitation test bed. Bull. Amer. Meteor. Soc., 93, 811-829, https://doi.org/10.1175/ BAMS-D-11-00052.1.

Rogers, R. R., 1971: The effect of variable target reflectivity on weather radar measurements. Quart. J. Roy. Meteor. Soc., 97, 154-167, https://doi.org/10.1002/qj.49709741203.

Rosenfeld, D., D. Atlas, and D. B. Wolff, 1992: Beamwidth effects on $Z-R$ relations and area-integrated rainfall. J. Appl. Meteor., 31, 454-464, https://doi.org/10.1175/15200450(1992)031<0454:BEOZRR > 2.0.CO;2.

_ D. B. Wolff, and D. Atlas, 1993: General probability-matched relations between radar reflectivity and rain rate. J. Appl. Meteor., 32, 50-72, https://doi.org/10.1175/1520-0450(1993) $032<0050:$ GPMRBR $>2.0 . \mathrm{CO} ; 2$.

Schaake, J., A. Henkel, and S. Cong, 2004: Application of PRISM climatologies for hydrologic modeling and forecasting in the western U.S. 18th Conf. on Hydrology, Seattle, WA, Amer. Meteor. Soc., 5.3, https://ams.confex.com/ams/84Annual/ techprogram/paper_72159.htm.

Scofield, R. A., and R. J. Kuligowski, 2003: Status and outlook of operational satellite precipitation algorithms for extreme-precipitation events. Wea. Forecasting, 18, 1037-1051, https:/doi.org/10.1175/ 1520-0434(2003)018<1037:SAOOOS $>2.0 . C O ; 2$

Seo, D. J., and J. P. Breidenbach, 2002: Real-time correction of spatially nonuniform bias in radar rainfall data using rain gauge measurements. J. Hydrometeor., 3, 93-111, https://doi.org/ 10.1175/1525-7541(2002)003<0093:RTCOSN>2.0.CO;2.

Sevruk, B., 2005: Rainfall measurement: Gauges. Encyclopedia of Hydrological Sciences, M. G. Anderson, Ed., John Wiley \& Sons, 529-536.

Sieck, L. C., S. J. Burges, and M. Steiner, 2007: Challenges in obtaining reliable measurements of point rainfall. Water Resour. Res., 43, W01420, https://doi.org/10.1029/2005WR004519.

Smith, C. J., 1986: The reduction of errors caused by bright bands in quantitative rainfall measurements made using radar. J. Atmos. Oceanic Technol., 3, 129-141, https://doi.org/ 10.1175/1520-0426(1986)003<0129:TROECB > 2.0.CO;2.

Smith, J. A., and W. F. Krajewski, 1991: Estimation of the mean field bias of radar rainfall estimates. J. Appl. Meteor., 30, 397-412, https://doi.org/10.1175/1520-0450(1991)030<0397:EOTMFB > 2.0.CO;2.

— D. J. Seo, M. L. Baeck, and M. D. Hudlow, 1996: An intercomparison study of NEXRAD precipitation estimates. Water Resour. Res., 32, 2035-2045, https://doi.org/10.1029/96WR00270.

Steiner, M., J. A. Smith, S. J. Burges, C. V. Alonso, and R. W. Darden, 1999: Effect of bias adjustment and rain gauge data 
quality control on radar rainfall estimation. Water Resour. Res., 35, 2487-2503, https://doi.org/10.1029/1999WR900142.

Stenz, R., X. Dong, and B. Xi, 2016: Improving satellite quantitative precipitation estimation using GOES-retrieved cloud optical depth. J. Hydrometeor., 17, 557-570, https://doi.org/ 10.1175/JHM-D-15-0057.1.

Sun, J., and Coauthors, 2014: Use of NWP for nowcasting convective precipitation: Recent progress and challenges. Bull. Amer. Meteor. Soc., 95, 409-426, https://doi.org/10.1175/ BAMS-D-11-00263.1.

Tang, L., J. Zhang, C. Langston, J. Krause, K. Howard, and V. Lakshmanan, 2014: A physically based precipitationnonprecipitation radar echo classifier using polarimetric and environmental data in a real-time national system. Wea. Forecasting, 29, 1106-1119, https://doi.org/10.1175/ WAF-D-13-00072.1.

Wang, Y., S. Cocks, L. Tang, A. Ryzhkov, P. Zhang, J. Zhang, and K. Howard, 2019: A prototype quantitative precipitation estimation algorithm for operational S-band polarimetric radar utilizing specific attenuation and specific differential phase. Part I: Algorithm description. J. Hydrometeor., 20, 985-997, https://doi.org/10.1175/JHM-D-18-0071.1.

Wilson, J. W., and E. A. Brandes, 1979: Radar measurement of rainfall: A summary. Bull. Amer. Meteor. Soc., 60, 1048-1058, https://doi.org/10.1175/1520-0477(1979)060<1048:RMORS> 2.0.CO;2.

Yang, D., B. E. Goodison, J. R. Metcalfe, V. S. Golubev, R. Bates, T. Pangburn, and C. L. Hanson, 1998: Accuracy of NWS 8", standard nonrecording precipitation gauge: Results and application of WMO intercomparison. J. Atmos. Oceanic Technol., 15, 54-68, https://doi.org/10.1175/1520-0426(1998) $015<0054$ :AONSNP $>2.0$. CO;2.

Young, C. B., B. R. Nelson, A. A. Bradley, J. A. Smith, C. D. Peters-Lidard, A. Kruger, and M. L. Baeck, 1999: An evaluation of NEXRAD precipitation estimates in complex terrain. J. Geophys. Res., 104, 19691-19703, https://doi.org/10.1029/ 1999JD900123.
—, A. A. Bradley, W. F. Krajewski, and A. Kruger, 2000: Evaluating NEXRAD multisensor precipitation estimates for operational hydrologic forecasting. J. Hydrometeor., 1, 241-254, https://doi.org/10.1175/1525-7541(2000)001<0241:ENMPEF> 2.0.CO;2.

Yussouf, N., J. S. Kain, and A. J. Clark, 2016: Short-term probabilistic forecasts of the 31 May 2013 Oklahoma tornado and flash flood event using a continuous-update-cycle storm-scale ensemble system. Wea. Forecasting, 31, 957-983, https:// doi.org/10.1175/WAF-D-15-0160.1.

Zawadzki, I., 1984: Factors affecting the precision of radar measurement of rain. Preprints, 22nd Int. Conf. on Radar Meteorology, Zurich, Switzerland, Amer. Meteor. Soc., 251-256.

Zhang, J., and Y. Qi, 2010: A real-time algorithm for the correction of brightband effects in radar-derived QPE. J. Hydrometeor., 11, 1157-1171, https://doi.org/10.1175/2010JHM1201.1.

, K. Howard, C. Langston, and B. Kaney, 2012a: Radar Quality Index (RQI) - A combined measure of beam blockage and VPR effects in a national network. IAHS Publ., 351, 388-393.

$\longrightarrow,-$, D. Kingsmill, and K. Howard, 2012b: Radar-based quantitative precipitation estimation for the cool season in complex terrain: Case studies from the NOAA Hydrometeorological Testbed. J. Hydrometeor., 13, 1836-1854, https:/doi.org/10.1175/ JHM-D-11-0145.1.

, — C C. Langston, B. Kaney, and K. Howard, 2014: A real-time algorithm for merging radar QPEs with rain gauge observations and orographic precipitation climatology. J. Hydrometeor., 15, 1794-1809, https://doi.org/10.1175/JHM-D-13-0163.1.

, and Coauthors, 2016: Multi-Radar Multi-Sensor (MRMS) quantitative precipitation estimation: Initial operating capabilities. Bull. Amer. Meteor. Soc., 97, 621-638, https://doi.org/ 10.1175/BAMS-D-14-00174.1.

, L. Tang, S. Cocks, P. Zhang, A. Ryzhkov, K. Howard, C. Langston, and B. Kaney, 2020: A dual-polarization radar synthetic QPE for operations. J. Hydrometeor., https://doi.org/ 10.1175/JHM-D-19-0194.1, in press. 